\title{
Logistic regression and machine learning predicted patient mortality from large sets of diagnosis codes comparably
}

Thomas E. Cowling ${ }^{\mathrm{a}, \mathrm{b}, *}$, David A. Cromwell ${ }^{\mathrm{a}, \mathrm{b}}$, Alexis Bellot ${ }^{\mathrm{c}, \mathrm{d}}$, Linda D. Sharples ${ }^{\mathrm{e}}$, Jan van der Meulen ${ }^{\mathrm{a}, \mathrm{b}}$

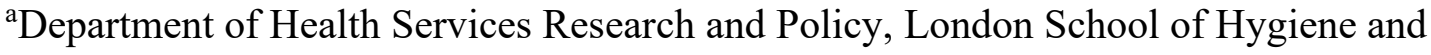
Tropical Medicine, Keppel St, London, WC1E 7HT, UK

${ }^{\mathrm{b}}$ Clinical Effectiveness Unit, Royal College of Surgeons of England, Lincoln's Inn Fields, London, WC2A 3PE, UK

'Department of Applied Mathematics and Theoretical Physics, University of Cambridge, Wilberforce Road, Cambridge, CB3 0WA, UK

${ }^{\mathrm{d}}$ Alan Turing Institute, 96 Euston Road, London, NW1 2DB, UK

${ }^{e}$ Department of Medical Statistics, London School of Hygiene and Tropical Medicine, Keppel St, London, WC1E 7HT, UK

*Corresponding author. London School of Hygiene and Tropical Medicine, Keppel St, London, WC1E 7HT, UK. Tel: +44 (0)20 7927 2151. E-mail: thomas.cowling@1shtm.ac.uk 


\begin{abstract}
Objective: To compare the performance of logistic regression and boosted trees for predicting patient mortality from large sets of diagnosis codes in electronic healthcare records.

Study Design and Setting: We analysed national hospital records and official death records for patients with myocardial infarction $(n=200,119)$, hip fracture $(n=169,646)$, or colorectal cancer surgery $(n=56,515)$ in England in 2015-17. One-year mortality was predicted from patient age, sex, and socioeconomic status, and 202 to 257 International Classification of Diseases $10^{\text {th }}$ Revision codes recorded in the preceding year or not (binary predictors). Performance measures included the $c$ statistic, scaled Brier score, and several measures of calibration.
\end{abstract}

Results: One-year mortality was 17.2\% (34,520) after myocardial infarction, $27.2 \%(46,115)$ after hip fracture, and 9.3\% $(5,273)$ after colorectal surgery. Optimism-adjusted $c$-statistics for the logistic regression models were 0.884 (95\% CI 0.882, 0.886), $0.798(0.796,0.800)$, and $0.811(0.805,0.817)$. The equivalent $c$-statistics for the boosted tree models were 0.891 (95\% CI 0.889, 0.892), 0.804 $(0.802,0.806)$, and $0.803(0.797,0.809)$. Model performance was also similar when measured using scaled Brier scores. All models were well calibrated overall.

Conclusion: In large datasets of electronic healthcare records, logistic regression and boosted tree models of numerous diagnosis codes predicted patient mortality comparably.

Key words: Machine learning, regression analysis, big data, electronic health records, International Classification of Diseases, comorbidity, prognosis

Running title: Logistic regression, machine learning, and large sets of diagnosis codes 


\section{What is new?}

\section{Key findings}

- Logistic regression and boosted trees predicted one-year mortality from large sets of diagnosis codes comparably, in three large and diverse clinical populations

\section{What this adds to what was known}

- Machine learning approaches have been used to model interactions between many diagnosis codes in large datasets of electronic healthcare records

- No previous studies have directly compared regression and machine learning approaches for modelling large sets of individual International Classification of Diseases (ICD) codes

\section{What should change now?}

- Our results suggest that there is little or no advantage to using machine learning rather than regression approaches in this particular study context 


\section{Introduction}

Machine learning has received increasing interest from epidemiologists, clinicians, and health services researchers in recent years. ${ }^{1-3}$ Related methods have been applied to various types of data, including gene sequences, medical images, and electronic healthcare records. ${ }^{4-6}$ While some commentators have emphasised the promise of these methods, ${ }^{7,8}$ others have focused on associated challenges. ${ }^{9,10}$

One area where the value of machine learning is particularly unclear is clinical prediction modelling. ${ }^{11-13}$ Prediction models can be used to inform clinical decisions and the design of preventive interventions, and they can also contribute to risk adjustment and causal inference methods. ${ }^{14,15}$ Predicting future events is a traditional focus of machine learning methods, which typically estimate relationships between variables more flexibly than conventional regression. ${ }^{16}$ While this may reduce bias in predictions, it could also increase the risk of modelling associations in the data that exist only by chance such that a model's predictions do not work well for future patients ('overfitting'). ${ }^{11}$

Electronic healthcare records offer growing opportunities to develop prediction models using machine learning, as large populations can often be studied using these records and larger samples reduce the risk of model overfitting. ${ }^{11,17}$ Several models have been developed with related methods and large datasets of electronic healthcare records. ${ }^{18-22}$ These models often include variables for hundreds of diagnosis codes to better capture the complexities of patient morbidity, including potential interactions across many conditions that may be best modelled by flexible methods. ${ }^{23,24}$ Regression models with many additive coefficients may be liable to predict some values that are too extreme.

However, it is often unclear how conventional regression methods would have performed if directly compared to the machine learning methods used in these studies. A recent systematic review ${ }^{25}$ of prognostic modelling studies that compared logistic regression and machine learning methods was limited by the small sample sizes and few predictor variables used in these studies. The review recommended that future research should examine the specific study contexts in which different approaches are suitable, particularly using large datasets and more predictors. ${ }^{25}$ 
In this study, we compared the performance of logistic regression and boosted tree models for predicting patient outcomes from large sets of diagnosis codes given in electronic healthcare records. Such models have been used to measure patient comorbidity and to adjust measures of healthcare quality for patient case-mix, for example. ${ }^{23,26}$ To do this, we analysed linked national datasets of routinely collected hospital data and official death records from England.

The study populations were patients admitted for acute myocardial infarction, hip fracture, or major surgery for colorectal cancer. We chose these populations partly because they represent many admissions, thus providing relevance to a wide audience and allowing robust internal validation of the models. These populations also vary in terms of clinical specialty, co-existing conditions, and mortality, which helped to assess the consistency of results across diverse groups.

We focused on boosted trees as the machine learning approach because they are often used for prediction modelling in large routinely collected healthcare datasets, ${ }^{6,22,27}$ they are well-established as a leading approach to tabular data in machine learning competitions,${ }^{28}$ and they can be used widely without advanced computing facilities due to quick fitting procedures. ${ }^{29}$

\section{Methods}

\subsection{Study populations}

We analysed Hospital Episode Statistics Admitted Patient Care data_-administrative data for all inpatient hospital care funded by the National Health Service (NHS) in England. ${ }^{30}$ Each record relates to an 'episode' of care under the same senior clinician and contains 20 fields for International Classification of Diseases $10^{\text {th }}$ Revision (ICD-10) $\operatorname{codes}^{31}$ relevant to that episode. The first field contains the primary diagnosis - the main condition treated.

Myocardial infarction (I21-22 32,33$)$ and hip fracture (S72.0-S72.2 $\left.2^{34,35}\right)$ patients were identified from ICD-10 codes recorded as the primary diagnosis in the first episode of each admission. Colorectal 
surgery patients were identified from any episode with both a relevant primary diagnosis (ICD-10: C18-20) and main procedure (OPCS-4: H04-11, H29, H33, X14). ${ }^{36-39}$

We included patients aged 18 years or older or, for hip fracture, only patients aged 60 years or older ${ }^{35}$ whose admission was from 1 January 2015 to 31 December 2017. If a patient had two or more admissions for the same index condition in this period (myocardial infarction, hip fracture, or colorectal surgery), only the first was included in the analysis.

\subsection{Outcome}

The outcome was death up to and including 365 days after the date of admission or, for colorectal surgery, the date of procedure. Mortality is the outcome most often used to assess models of diagnosis codes in hospital settings and to develop prediction models using electronic healthcare records. ${ }^{17,24,40}$ We analysed 365-day mortality, rather than in-hospital or 30-day mortality for example, to increase the effective sample size (which is related to the number of outcome events ${ }^{41}$ ).

We used dates of death recorded in Office for National Statistics mortality data ${ }^{42}$ up to 31 December 2018, providing complete follow-up for the outcome. These official records were linked to Hospital Episode Statistics based on each patient's unique NHS identifier, date of birth, sex, and postcode. ${ }^{43}$

\subsection{Predictors}

We defined a binary predictor for each ICD-10 code that denoted whether it was recorded or not in each patient's index episode or up to 365 days before. We analysed the first three characters of these codes (excluding fourth characters) as coding choices at this level will be less variable than with four characters. ${ }^{23}$ The first three characters define single conditions or other health-related attributes; fourth characters define sites, subtypes, and causes. ${ }^{44}$

In each population, we excluded three-character codes recorded for less than $0.5 \%$ of patients in the 365-day 'look-back period' as these codes were so rare that they were unlikely to improve model 
performance. ${ }^{6,26,45}$ We used a 365 -day period, rather than only using codes from the index episode, as this improved model performance in some published studies. ${ }^{24}$

Patient age, sex, and socioeconomic status were also included as predictors, as is common when examining models of ICD codes. ${ }^{24,40}$ Socioeconomic status was measured by the national Index of Multiple Deprivation rank of each residential area (with 1000 to 3000 residents in each of 32482 areas $)^{46}$; we excluded patients with missing data for this variable $(1.2 \% ; 5346 / 431626)$.

\subsection{Model estimation}

We first estimated associations between the outcome and predictors (age, sex, socioeconomic status, and ICD codes) as the maximum likelihood estimates of a logistic regression model. We did not fit non-linear associations for age or socioeconomic status or use penalised estimation, as these choices had minimal effects on model performance in our previous analysis of the same data. ${ }^{47}$

We used the XGBoost ${ }^{29}$ algorithm to develop gradient boosted tree models, ${ }^{48-50}$ using all predictors as before. This algorithm fits a series of tree models to the data sequentially with each tree attempting to improve on predictions from the previous tree..$^{51}$ These models fit many interactions between predictors without these terms having to be pre-specified (unlike in conventional regression).

Five boosted tree models were fitted in each population using 100, 200, 300, 400, and 500 boosting iterations. Further tuning parameters were held fixed as various combinations of these parameters gave similar maximum performance across this range of boosting iterations (see Appendix A1). The learning rate, maximum tree depth, minimum node weight, and subsample fraction took the values of $0.1,5,100$, and 1 , respectively (see Appendix A1 for definitions).

\subsection{Model performance}

Overall model performance was measured using Brier scores. ${ }^{52}$ These scores equalled the mean of squared differences between predicted probabilities of death and observed outcomes. We scaled these scores from $0-100 \%$ ( $0 \%$ for a non-informative model and $100 \%$ if perfect $).{ }^{53}$ 
To assess discrimination, we calculated the $c$-statistic. This equalled the probability that a randomly chosen patient who died had a greater predicted probability of death than a randomly chosen patient who did not. ${ }^{54}$ The $c$-statistic equals one for perfect models and 0.5 for predictions made at random.

To assess calibration, we calculated the integrated calibration index (ICI) ${ }^{55}$ calibration-in-the-large, and calibration slopes. ${ }^{56}$ ICI and calibration-in-the-large assess the calibration of model predictions across their range and overall, respectively; perfect models have values of zero. Calibration slopes equal one in perfect models, with smaller values indicating overfitting.

For each model in each population, we first calculated the above measures in the original data used to fit the models ('apparent performance'). We then repeated all modelling steps in each of 250 bootstrap samples and, for each sample, calculated the performance of the resulting model in this sample and the original data; the difference in performance values between the bootstrap sample and original data defined the 'optimism'. Finally, an optimism-adjusted value of each performance measure was calculated as the apparent performance value minus the mean optimism. ${ }^{54,57,58}$ This is the bootstrap validation approach given in the TRIPOD guidelines. ${ }^{59}$

\subsection{Secondary analyses}

We conducted a secondary analysis using a 1825-day (five-year) look-back period. This analysis also accounted for the exact number of days since each ICD-10 code was last recorded rather than just whether it was recorded or not in a given time period (see Appendix A2 for details). This analysis, in addition to the main analysis, was pre-specified in a published protocol ${ }^{60} \mathrm{We}$ have previously reported a separate study that was specified in the same protocol. ${ }^{47}$

We conducted two post-hoc analyses (also described in Appendix A2). In the first analysis, we examined whether the calibration of the logistic regression models at high predicted probabilities could be improved. We used splines to fit non-linear associations for age and socioeconomic status and included interactions between three selected predictors. In the second analysis, we assessed the 
performance of two additional machine learning approaches — random forests and neural networks. Data preparation was done using Stata (v15). R (v3.5) was used for all analysis; code to implement the different estimation methods is given in Appendix A3.

In response to a peer reviewer's suggestion, we conducted two additional analyses. First, we added 500 extra boosting iterations (1000 in total) and used other combinations of tuning parameters to see if this improved the boosted trees' performance. Second, we examined the performance of the regression and boosted tree models when only ICD codes with frequencies less than $0.1 \%$ (rather than $0.5 \%)$ were excluded from the set of predictor variables.

\section{Results}

The percentage of patients who died within one year was 17.2\% (34 520/200 119) after myocardial infarction, 27.2\% (46 115/169 646) after hip fracture, and 9.3\% (5273/56 515) after colorectal surgery. In each population, between 202 and 257 ICD-10 codes were recorded for at least $0.5 \%$ of patients within one year before their admission or procedure. This provided 168 (34 520/205; myocardial infarction), 177 (46 115/260; hip fracture), and 25 (5273/212; colorectal surgery) deaths per predictor variable. Most ICD-10 codes had low frequencies (see Table 1).

The distributions of predicted probabilities were similar between the logistic regression and boosted tree models overall (Figure 1; see Figure 2 for distributions by outcome). The most 'important' variables were also similar between models (Appendix A4). Age and metastatic cancer in the respiratory and digestive organs were important predictors of death in each population.

The overall optimism-adjusted performance of the boosted trees was slightly better than that of logistic regression, as measured by Brier scores, in the myocardial infarction and hip fracture populations (Table 2). The absolute differences in scaled Brier scores were 1.9\% (95\% CI: 1.7\% to $2.1 \%)$ and $1.2 \%(95 \%$ CI: $1.0 \%$ to $1.4 \%)$ respectively. Logistic regression had a slightly superior 
score in the colorectal surgery population (difference $=1.5 \%$; $95 \%$ CI: $0.8 \%$ to $2.1 \%$ ). Model discrimination, as measured by the $c$-statistic, followed the same pattern with a minimum value of 0.798 (95\% CI: 0.796 to 0.800 ) across models and populations (see Table 2).

Both the boosted trees and regression models were well calibrated overall. Values of calibration-inthe-large and calibration slopes were close to their respective ideal values of 0 and 1 (Table 2).

However, logistic regression predictions of very high probabilities of death were too high on average, particularly in the colorectal surgery population (see calibration plots in Figure 3). In contrast, the predictions of the boosted trees closely agreed with observed outcomes across the range of predicted probabilities. Several ICD-10 codes were frequent amongst patients with very high predicted risks of death and these codes were almost identical for the boosted trees and regression models (see Appendix A5 for code frequencies in the top 5\% of predicted risks). The inclusion of splines and interactions between selected codes in the logistic regression models did not correct for the worse calibration observed at high predicted risks in each population (Appendix A6).

For the boosted tree models, the maximum scaled Brier scores were attained with 500 boosting iterations in the myocardial infarction and hip fracture populations and 200 iterations in the colorectal surgery population (Appendix A7). These numbers of iterations also provided the models whose calibration slopes were closest to 1 (the ideal value). The differences between apparent and optimismadjusted performance (optimism) were typically small for the boosted tree models but the corresponding differences for logistic regression were even smaller (Appendix A7).

The models estimated in the secondary analysis using a five-year look-back period generally performed similarly to or not as well as those from the main analysis (Appendix A8). The random forest models did not attain scaled Brier scores or $c$-statistics that were greater than those for both the logistic regression and boosted tree models in any of the populations, while the neural networks were the worst-performing models in each population (see Appendix A8 for results). Using up to 1000 boosting iterations for the boosted tree models and other combinations of tuning parameters did not 
improve prediction performance, neither did using a $0.1 \%$ (versus $0.5 \%$ ) frequency threshold for including ICD codes as predictors (Appendix A9).

\section{Discussion}

In large datasets of electronic healthcare records, logistic regression and boosted tree models of numerous diagnosis codes predicted one-year mortality comparably. This was consistent across the three populations of acute myocardial infarction, hip fracture, and colorectal surgery patients. Both the logistic regression and boosted tree models had good discrimination and were well calibrated overall, though the boosted trees were better calibrated at high predicted probabilities of death.

\subsection{Interpretation of results}

A potential strength of boosted trees is that they include many interactions between predictors by design. Interactions across many conditions were plausible given relationships between disorders and their management. Several authors have advocated modelling interactions between conditions for this reason. ${ }^{23,24,61}$ However, the boosted trees performed comparably to logistic regression models without interactions, suggesting that interactions were unimportant overall in this context.

This finding may be partly explained by the low frequencies of most ICD codes. Two codes may not be recorded together very often which reduces the potential for their interaction to improve overall model performance, even if the interaction has a large true prognostic effect. It may also be difficult to reliably estimate interactions between codes that are not often recorded together.

Clinical prediction problems have been described as having unfavourable 'signal-to-noise' ratios that question the potential benefits of using more flexible estimation methods that fit many interactions. ${ }^{62}$ Misclassification error in the recording of diagnosis codes may add to the 'noise' and result in biased estimates of true interactions. In addition, more flexible methods may be more likely to capture spurious relationships in the data that have arisen by chance. However, the values of optimism for the 
boosted trees were reasonably small in the current study which is partly explained by the large sample sizes and the shrinkage included in the boosting process to prevent model overfitting.

Larger study populations reduce the potential for overfitting and can thereby improve the performance of more flexible methods. ${ }^{63} \mathrm{We}$ used three years of national data to provide large samples, but many investigators do not have access to such large databases. ${ }^{11}$ In smaller populations or when the study outcome occurs less frequently, any benefits of boosted trees over logistic regression in terms of prediction performance are likely to reduce. In addition, important interactions may already be known such that they could be pre-specified in regression models.

One benefit of the boosted trees was that very high predicted probabilities were better calibrated than when logistic regression was used. This was not fully explained by the splines or interactions that were added to the regression models, which may be because interactions between many codes needed to be added. Boosted trees fit interactions in each iteration to improve predictions where the existing model works less well, such as extreme cases. In contrast, logistic regression models may fit well overall but are not designed to capture unusual cases with very high risks of death because the many patients at low risk dominate model estimates. However, interactions fitted by boosted trees may not be generalisable to other datasets which could reduce this benefit.

\subsection{Relation to existing literature}

To our knowledge, no previous studies have directly compared regression and machine learning approaches for modelling large sets of individual ICD codes specifically. In a previous study of Hospital Episode Statistics data (up to 2013), logistic regression models had similar discrimination to support vector machines, neural networks, and random forests when predicting in-hospital mortality using small sets of comorbidities. ${ }^{64}$ Using the same datasets as in the current study, we have previously found that large sets of individual ICD codes can predict patient outcomes better than traditional sets of comorbidities, ${ }^{47}$ which is consistent with other studies. ${ }^{23,26,65}$ 
Many analyses have compared logistic regression with boosted trees and other machine learning approaches in various large datasets of electronic healthcare records, with differing results (for example $22,27,62,66,67)$. Two studies ${ }^{22,27}$ in which boosted trees performed better than regression analysed large primary care datasets, which may suggest that boosted trees have an advantage in very heterogeneous populations. This contrasts to our analysis which was done within populations defined by an index condition. It is difficult to draw general conclusions from such studies, as results may be sensitive to the specific prediction problem (such as sample size, predictors, and data quality) and the exact implementation of algorithms. One approach will not work best across all contexts. ${ }^{68,69}$

A recent systematic review ${ }^{25}$ of studies that compared logistic regression and machine learning for clinical prediction modelling stated that 'Future research should focus more on delineating the type of predictive problems in which various algorithms have maximal value' (p.18). Our study aligns with this call and suggests that logistic regression and boosted trees predict patient mortality comparably from numerous diagnosis codes in large electronic healthcare datasets.

\subsection{Limitations of the study}

Our study focused on diagnosis codes given their central role in analysing patient morbidity using electronic healthcare records. In addition, the ICD-10 coding system has a standardised core format internationally which may improve the generalisability of our results to other countries. Future work could include other predictors that are likely to have strong effects but may be recorded variably or not at all in the datasets of different countries, such as the hospitalisation pathway. Some variables modelled in other studies using boosted trees, including laboratory test values and prescription information, ${ }^{21,27}$ are not recorded in Hospital Episode Statistics data.

Future research should conduct similar comparisons for other populations, outcomes, and datasets to see whether our results apply more generally. For example, in study populations without a defined index condition, interactions between primary and secondary diagnosis codes may improve prediction performance. In large datasets with greater frequencies of ICD codes, possibly in older populations, interactions between codes may be estimated with greater precision. The external validity of models 
produced using regression and machine learning approaches should also be compared when investigators intend to use the models in another dataset or context.

\subsection{Implications for research}

Many studies use diagnosis codes from electronic healthcare records to model patient morbidity. ${ }^{70}$ Our results suggest that there is little or no advantage to using machine learning rather than regression approaches in the particular context examined. Investigators may prefer to use regression instead if they require a model that is transparent, easily interpreted, and familiar to a wide audience. We have previously reported a regression-based approach for selecting small sets of ICD codes with high prediction performance. ${ }^{47}$

Electronic healthcare records are increasing in volume and scope, presenting growing opportunities to use large sets of predictors and model their relationships with more flexible methods. ${ }^{17}$ High-quality comparisons in large datasets are required to determine the contexts in which these methods should be used and when more conventional approaches are sufficient. ${ }^{25}$ In the context of the study presented here, our results suggest that regression approaches perform well. 


\section{Funding}

T.E.C. was supported by the Medical Research Council (grant number MR/S020470/1). The funder had no role in study design; in the collection, analysis and interpretation of data; in the writing of the report; and in the decision to submit the article for publication.

\section{CRediT authorship contribution statement}

T.E.C.: Conceptualization, Methodology, Software, Validation, Formal Analysis, Investigation, Data Curation, Writing - Original Draft, Writing - Review \& Editing, Visualization, Funding acquisition. D.A.C.: Methodology, Resources, Writing - Review \& Editing. A.B.: Methodology, Writing Review \& Editing. L.D.S.: Methodology, Writing - Review \& Editing. J.v.d.M.: Methodology, Writing - Review \& Editing.

\section{Conflicts of Interest}

None declared.

\section{Data statement}

The study was exempt from UK National Research Ethics Service (NRES) approval because it involved the analysis of an existing dataset of anonymised data. Hospital Episode Statistics (HES) data were made available by NHS Digital (Copyright 2019, re-used with the permission of NHS

Digital. All rights reserved.) Approvals for the use of anonymised HES data were obtained as part of the standard NHS Digital data access process. The data governance arrangements for the study do not allow us to redistribute HES data to other parties. Researchers interested in accessing HES data can apply for access through NHS Digital's Data Access Request Service (DARS) https://dataaccessrequest.hscic.gov.uk/. 


\section{References}

1. Beam AL, Kohane IS. Big Data and Machine Learning in Health Care. JAMA 2018;319:1317-8.

2. Rajkomar A, Dean J, Kohane I. Machine Learning in Medicine. N Engl J Med 2019;380:1347-58.

3. Rose S. Intersections of machine learning and epidemiological methods for health services research. Int $J$ Epidemiol 2020. doi: 10.1093/ije/dyaa035.

4. Zou J, Huss M, Abid A, Mohammadi P, Torkamani A, Telenti A. A primer on deep learning in genomics. Nat Genet 2019;51:12-8.

5. Gulshan V, Peng L, Coram M, et al. Development and Validation of a Deep Learning Algorithm for Detection of Diabetic Retinopathy in Retinal Fundus Photographs. JAMA 2016;316:2402-10.

6. Einav L, Finkelstein A, Mullainathan S, Obermeyer Z. Predictive modeling of U.S. health care spending in late life. Science 2018;360:1462-5.

7. Obermeyer Z, Emanuel EJ. Predicting the Future - Big Data, Machine Learning, and Clinical Medicine. $N$ Engl $J$ Med 2016;375:1216-9.

8. Hinton G. Deep Learning-A Technology With the Potential to Transform Health Care. JAMA 2018;320:1101-2.

9. Chen JH, Asch SM. Machine Learning and Prediction in Medicine - Beyond the Peak of Inflated Expectations. $N$ Engl J Med 2017;376:2507-9.

10. Cabitza F, Rasoini R, Gensini GF. Unintended Consequences of Machine Learning in Medicine. JAMA 2017;318:517-8.

11. Steyerberg EW. Clinical Prediction Models: A Practical Approach to Development, Validation, and Updating. 2nd ed. Cham: Springer; 2019.

12. Van Calster B, Wynants L. Machine Learning in Medicine. N Engl J Med 2019;380:2588.

13. Collins GS, Moons KGM. Reporting of artificial intelligence prediction models. Lancet 2019;393:1577-9.

14. Steyerberg EW, Moons KG, van der Windt DA, et al. Prognosis Research Strategy (PROGRESS) 3: prognostic model research. PLoS Med 2013;10:e1001381. doi: 10.1371/journal.pmed.1001381.

15. Blakely T, Lynch J, Simons K, Bentley R, Rose S. Reflection on modern methods: when worlds collide-prediction, machine learning and causal inference. Int J Epidemiol 2019. doi: 10.1093/ije/dyz132.

16. Hastie T, Tibshirani R, Friedman J. The Elements of Statistical Learning: Data Mining, Inference, and Prediction. 2nd ed. New York: Springer; 2009.

17. Goldstein BA, Navar AM, Pencina MJ, Ioannidis JP. Opportunities and challenges in developing risk prediction models with electronic health records data: a systematic review. J Am Med Inform Assoc 2017;24:198-208.

18. Avati A, Jung K, Harman S, Downing L, Ng A, Shah NH. Improving palliative care with deep learning. BMC Med Inform Decis Mak 2018;18:122. doi: 10.1186/s12911-018-0677-8.

19. Rajkomar A, Oren E, Chen K, et al. Scalable and accurate deep learning with electronic health records. Npj Digital Medicine 2018;1:18. doi: 10.1038/s41746-018-0029-1.

20. Steele AJ, Denaxas SC, Shah AD, Hemingway H, Luscombe NM. Machine learning models in electronic health records can outperform conventional survival models for predicting patient mortality in coronary artery disease. PLoS One 2018;13:e202344. doi: 10.1371/journal.pone.0202344.

21. Elfiky AA, Pany MJ, Parikh RB, Obermeyer Z. Development and Application of a Machine Learning Approach to Assess Short-term Mortality Risk Among Patients With Cancer Starting Chemotherapy. JAMA Netw Open 2018;1:e180926. doi: 10.1001/jamanetworkopen.2018.0926. 
22. Jung K, Sudat SEK, Kwon N, Stewart WF, Shah NH. Predicting Need for Advanced Illness or Palliative Care In A Primary Care Population Using Electronic Health Record Data. J Biomed Inform 2019:103115. doi:

10.1016/j.jbi.2019.103115.

23. Holman CD, Preen DB, Baynham NJ, Finn JC, Semmens JB. A multipurpose comorbidity scoring system performed better than the Charlson index. J Clin Epidemiol 2005;58:1006-14.

24. Sharabiani MT, Aylin P, Bottle A. Systematic review of comorbidity indices for administrative data. Med Care 2012;50:1109-18.

25. Christodoulou E, Ma J, Collins GS, Steyerberg EW, Verbakel JY, Van Calster B. A systematic review shows no performance benefit of machine learning over logistic regression for clinical prediction models. J Clin Epidemiol $2019 ; 110: 12-22$.

26. Krumholz HM, Coppi AC, Warner F, et al. Comparative Effectiveness of New Approaches to Improve Mortality Risk Models From Medicare Claims Data. JAMA Netw Open 2019;2:e197314. doi: 10.1001/jamanetworkopen.2019.7314.

27. Rahimian F, Salimi-Khorshidi G, Payberah AH, et al. Predicting the risk of emergency admission with machine learning: Development and validation using linked electronic health records. PLOS Medicine 2018;15:e1002695. doi: 10.1371/journal.pmed.1002695.

28. Kaggle. What is XGBoost. Available from: https://www.kaggle.com/dansbecker/xgboost.

29. Chen T, Guestrin C. XGBoost: A Scalable Tree Boosting System. arXiv 2016. doi: 10.1145/2939672.2939785.

30. Herbert A, Wijlaars L, Zylbersztejn A, Cromwell D, Hardelid P. Data Resource Profile: Hospital Episode Statistics Admitted Patient Care (HES APC). Int J Epidemiol 2017;46:1093-i. doi: 10.1093/ije/dyx015.

31. World Health Organization. International Statistical Classification of Diseases and Related Health Problems 10th revision (5th edition). 2016. Available from:

https://icd.who.int/browse10/Content/statichtm1/ICD10Volume2 en 2016.pdf.

32. Metcalfe A, Neudam A, Forde S, et al. Case definitions for acute myocardial infarction in administrative databases and their impact on in-hospital mortality rates. Health Serv Res 2013;48:290-318.

33. McCormick N, Lacaille D, Bhole V, Avina-Zubieta JA. Validity of myocardial infarction diagnoses in administrative databases: a systematic review. PLoS One 2014;9:e92286. doi: 10.1371/journal.pone.0092286.

34. Toson B, Harvey LA, Close JC. The ICD-10 Charlson Comorbidity Index predicted mortality but not resource utilization following hip fracture. J Clin Epidemiol 2015;68:44-51.

35. Royal College of Physicians. National Hip Fracture Database (NHFD) annual report 2016. 2016. Available from: https://www.nhfd.co.uk/report2016.

36. Burns EM, Bottle A, Aylin P, Darzi A, Nicholls RJ, Faiz O. Variation in reoperation after colorectal surgery in England as an indicator of surgical performance: retrospective analysis of Hospital Episode Statistics. BMJ 2011;343:d4836. doi: $10.1136 /$ bmj.d4836.

37. Byrne BE, Mamidanna R, Vincent CA, Faiz O. Population-based cohort study comparing 30- and 90-day institutional mortality rates after colorectal surgery. Br J Surg 2013;100:1810-7.

38. Morris EJ, Taylor EF, Thomas JD, et al. Thirty-day postoperative mortality after colorectal cancer surgery in England. Gut 2011;60:806-13.

39. Redaniel MT, Martin RM, Blazeby JM, Wade J, Jeffreys M. The association of time between diagnosis and major resection with poorer colorectal cancer survival: a retrospective cohort study. BMC Cancer 2014;14:642. doi: 10.1186/14712407-14-642.

40. Yurkovich M, Avina-Zubieta JA, Thomas J, Gorenchtein M, Lacaille D. A systematic review identifies valid comorbidity indices derived from administrative health data. J Clin Epidemiol 2015;68:3-14.

41. Riley RD, Snell KI, Ensor J, et al. Minimum sample size for developing a multivariable prediction model: PART II - binary and time-to-event outcomes. Stat Med 2018. doi: 10.1002/sim.7992. 
42. Office for National Statistics. Deaths. Available from:

https://www.ons.gov.uk/peoplepopulationandcommunity/birthsdeathsandmarriages/deaths.

43. NHS Digital. A Guide to Linked Mortality Data from Hospital Episode Statistics and the Office for National Statistics. Available from: https://digital.nhs.uk/data-and-information/data-tools-and-services/data-services/linked-hes-onsmortality-data.

44. World Health Organization. Classification of Diseases (ICD). Available from: https://www.who.int/classifications/icd/en/.

45. Austin PC, Steyerberg EW. Interpreting the concordance statistic of a logistic regression model: relation to the variance and odds ratio of a continuous explanatory variable. BMC Medical Research Methodology 2012;12:82. doi: $10.1186 / 1471-2288-12-82$.

46. Ministry of Housing, Communities \& Local Government,. English indices of deprivation. Available from: https://www.gov.uk/government/collections/english-indices-of-deprivation.

47. Cowling TE, Cromwell DA, Sharples LD, van der Meulen J. A novel approach selected small sets of diagnosis codes with high prediction performance in large healthcare datasets. J Clin Epidemiol 2020. doi:

10.1016/j.jclinepi.2020.08.001.

48. Friedman JH. Greedy function approximation: A gradient boosting machine. Annals of Statistics 2001;29:1189-

232.

49. Friedman J, Hastie T, Tibshirani R. Additive logistic regression: a statistical view of boosting (With discussion and a rejoinder by the authors). The Annals of Statistics 2000;28:337-407.

50. Friedman JH. Stochastic gradient boosting. Computational Statistics \& Data Analysis 2002;38:367-78.

51. Chen T, He T, Benesty M. XGBoost R Tutorial. Available from: https://cran.rproject.org/web/packages/xgboost/vignettes/xgboostPresentation.html.

52. Brier GW. Verification of Forecasts Expressed in Terms of Probability. Monthly Weather Review 1950;78:1-3.

53. Steyerberg EW, Vickers AJ, Cook NR, et al. Assessing the performance of prediction models: a framework for traditional and novel measures. Epidemiology 2010;21:128-38.

54. Harrell FE, Jr. Regression Modeling Strategies: With Applications to Linear Models, Logistic and Ordinal Regression, and Survival Analysis. 2nd ed. Cham: Springer; 2015.

55. Austin PC, Steyerberg EW. The Integrated Calibration Index (ICI) and related metrics for quantifying the calibration of logistic regression models. Stat Med 2019. doi: 10.1002/sim.8281.

56. Cox DR. Two further applications of a model for binary regression. Biometrika 1958;45:562-5.

57. Steyerberg EW, Harrell FE, Jr., Borsboom GJ, Eijkemans MJ, Vergouwe Y, Habbema JD. Internal validation of predictive models: efficiency of some procedures for logistic regression analysis. J Clin Epidemiol 2001;54:774-81.

58. Efron B, Tibshirani R. An Introduction to the Bootstrap. New York: Chapman \& Hall; 1993.

59. Moons KG, Altman DG, Reitsma JB, et al. Transparent Reporting of a multivariable prediction model for Individual Prognosis or Diagnosis (TRIPOD): explanation and elaboration. Ann Intern Med 2015;162:W1-73. doi: 10.7326/M14-0698.

60. Cowling TE, Cromwell DA, Sharples LD, van der Meulen J. Protocol for an observational study evaluating new approaches to modelling diagnostic information from large administrative hospital datasets. medRxiv 2019:19011338. doi: $10.1101 / 19011338$.

61. Romano PS, Roos LL, Jollis JG. Adapting a clinical comorbidity index for use with ICD-9-CM administrative data: differing perspectives. J Clin Epidemiol 1993;46:1075-9.

62. Ennis M, Hinton G, Naylor D, Revow M, Tibshirani R. A comparison of statistical learning methods on the Gusto database. Stat Med 1998;17:2501-8. 
63. van der Ploeg T, Austin PC, Steyerberg EW. Modern modelling techniques are data hungry: a simulation study for predicting dichotomous endpoints. BMC Med Res Methodol 2014;14:137. doi: 10.1186/1471-2288-14-137.

64. Bottle A, Gaudoin R, Goudie R, Jones S, Aylin P. Can valid and practical risk-prediction or casemix adjustment models, including adjustment for comorbidity, be generated from English hospital administrative data (Hospital Episode Statistics)? A national observational study. Southampton (UK): NIHR Journals Library; 2014.

65. Stanley J, Sarfati D. The new measuring multimorbidity index predicted mortality better than Charlson and Elixhauser indices among the general population. J Clin Epidemiol 2017;92:99-110.

66. Austin PC, Lee DS, Steyerberg EW, Tu JV. Regression trees for predicting mortality in patients with cardiovascular disease: what improvement is achieved by using ensemble-based methods? Biom J 2012;54:657-73.

67. Gravesteijn BY, Nieboer D, Ercole A, et al. Machine learning algorithms performed no better than regression models for prognostication in traumatic brain injury. J Clin Epidemiol 2020;122:95-107.

68. Wolpert DH. The Lack of A Priori Distinctions Between Learning Algorithms. Neural Computation 1996;8:134190.

69. Couronne R, Probst P, Boulesteix AL. Random forest versus logistic regression: a large-scale benchmark experiment. BMC Bioinformatics 2018;19:270. doi: 10.1186/s12859-018-2264-5.

70. Quan H, Sundararajan V, Halfon P, et al. Coding algorithms for defining comorbidities in ICD-9-CM and ICD-10 administrative data. Med Care 2005;43:1130-9. 
Table 1. Descriptive statistics for outcome and predictor variables, by population

\begin{tabular}{|c|c|c|c|}
\hline & $\begin{array}{r}\text { Acute myocardial } \\
\text { infarction }\end{array}$ & Hip fracture & $\begin{array}{r}\text { Major colorectal } \\
\text { cancer surgery }\end{array}$ \\
\hline Number of patients & 200119 & 169646 & 56515 \\
\hline Number who died within 1 year (\%) & $34520(17.2)$ & $46115(27.2)$ & $5273(9.3)$ \\
\hline \multicolumn{4}{|l|}{ Patient characteristics } \\
\hline Median age (IQR) & $70(58$ to 80$)$ & 84 (77 to 89$)$ & $70(62$ to 78$)$ \\
\hline Male (versus female) (\%) & $132162(66.0)$ & $48622(28.7)$ & $32004(56.6)$ \\
\hline Median socioeconomic status $(\mathrm{IQR})^{\mathrm{a}}$ & $4.8(2.4$ to 7.3$)$ & $5.4(2.9$ to 7.7$)$ & $5.7(3.3$ to 7.9$)$ \\
\hline \multicolumn{4}{|l|}{ ICD-10 codes } \\
\hline Number of codes included ${ }^{\mathrm{b}}$ & 202 & 257 & 209 \\
\hline Median frequency (\%) of codes (IQR) & $1.6(0.8$ to 3.4$)$ & $1.8(0.8$ to 4.2$)$ & $1.6(0.9$ to 4.5$)$ \\
\hline Median number of codes per patient (IQR) & $6(4$ to 10$)$ & $9(6$ to 14$)$ & $7(4$ to 11$)$ \\
\hline Median agreement between codes $(\mathrm{IQR})^{\mathrm{c}}$ & $0.01(0.00$ to 0.02$)$ & $0.01(0.00$ to 0.01$)$ & $0.01(0.00$ to 0.01$)$ \\
\hline
\end{tabular}


Table 2. Prediction performance of the logistic regression and boosted tree models, corrected for optimism using 250 bootstrap samples (with 95\% confidence intervals)

\begin{tabular}{|c|c|c|c|}
\hline & $\begin{array}{r}\text { Acute myocardial } \\
\text { infarction }\end{array}$ & Hip fracture & $\begin{array}{l}\text { Major colorectal } \\
\text { cancer surgery }\end{array}$ \\
\hline \multicolumn{4}{|l|}{ Scaled Brier score (\%) } \\
\hline Logistic regression & $34.6(34.2$ to 35.1$)$ & $22.8(22.4$ to 23.2$)$ & $17.2(16.1$ to 18.2$)$ \\
\hline Boosted trees & $36.5(36.1$ to 37.0$)$ & $24.0(23.6$ to 24.4$)$ & $15.7(14.8$ to 16.6$)$ \\
\hline \multicolumn{4}{|l|}{$c$-statistic } \\
\hline Logistic regression & $0.884(0.882$ to 0.886$)$ & $0.798(0.796$ to 0.800$)$ & $0.811(0.805$ to 0.817$)$ \\
\hline Boosted trees & $0.891(0.889$ to 0.892$)$ & $0.804(0.802$ to 0.806$)$ & $0.803(0.797$ to 0.809$)$ \\
\hline \multicolumn{4}{|c|}{ Calibration-in-the-large } \\
\hline Logistic regression & $-0.001(-0.017$ to 0.015$)$ & $0.000(-0.013$ to 0.013$)$ & $0.000(-0.032$ to 0.031$)$ \\
\hline Boosted trees & $0.000(-0.016$ to 0.016$)$ & $0.001(-0.012$ to 0.014$)$ & $0.002(-0.028$ to 0.033$)$ \\
\hline \multicolumn{4}{|l|}{ Calibration slope } \\
\hline Logistic regression & $0.993(0.984$ to 1.003$)$ & $0.989(0.977$ to 1.002$)$ & $0.961(0.936$ to 0.987$)$ \\
\hline Boosted trees & $1.003(0.993$ to 1.013$)$ & $1.006(0.993$ to 1.018$)$ & $0.988(0.963$ to 1.013$)$ \\
\hline \multicolumn{4}{|c|}{ Integrated calibration index } \\
\hline Logistic regression & $0.012(0.011$ to 0.013$)$ & $0.015(0.014$ to 0.017$)$ & $0.007(0.006$ to 0.009$)$ \\
\hline Boosted trees & $0.002(0.001$ to 0.003$)$ & $0.004(0.002$ to 0.006$)$ & $0.001(0.000$ to 0.003$)$ \\
\hline
\end{tabular}

Results for boosted trees correspond to models with 500 boosting iterations in the myocardial infarction and hip fracture populations and 200 iterations in the colorectal surgery population. 
Figure 1. Frequency distributions of predicted probabilities of death, by population and method

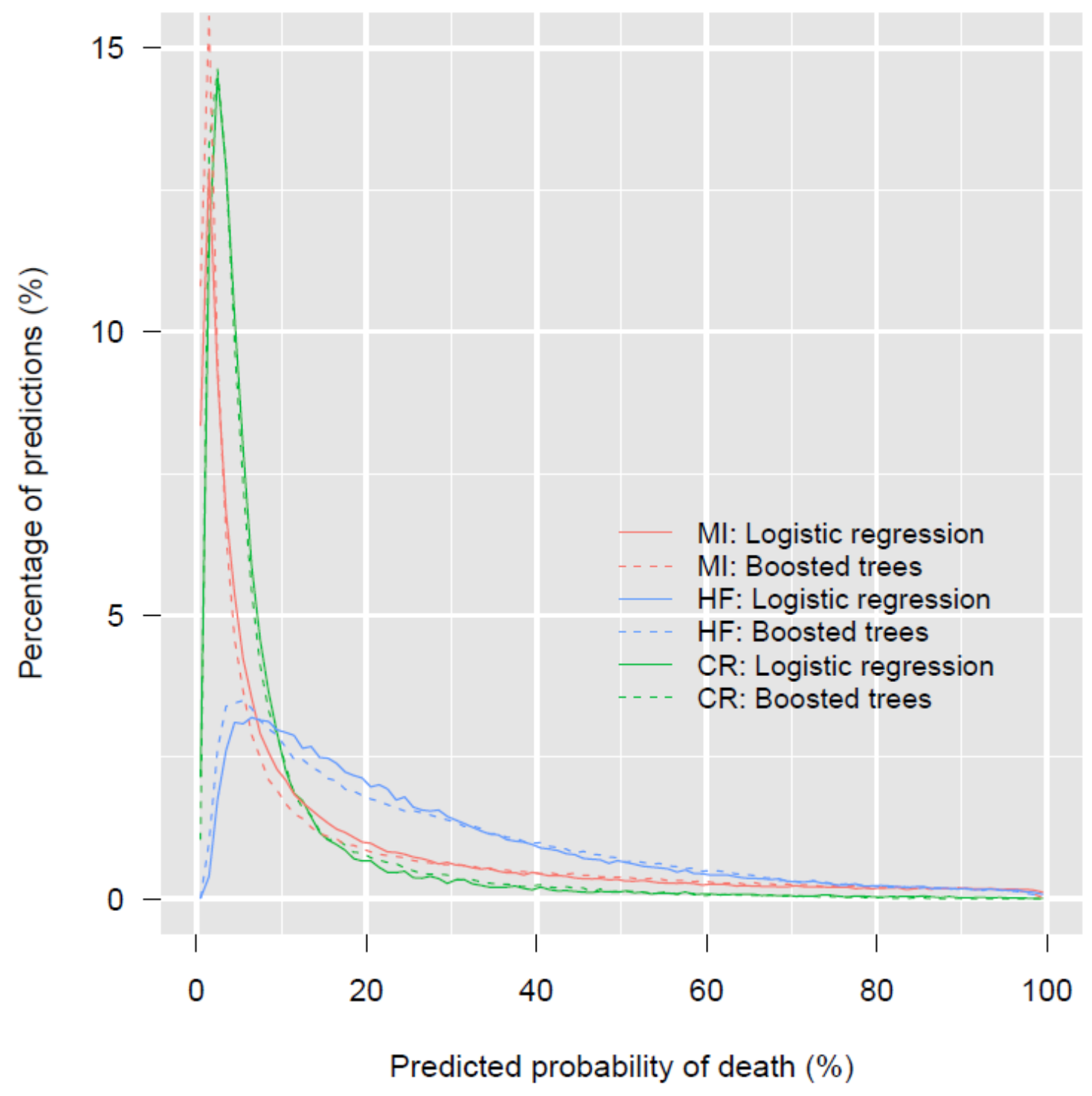

MI: myocardial infarction; HF: hip fracture; CR: colorectal surgery. In the MI population, 5\% of patients had predicted probabilities equal to or greater than $72.5 \%$. The corresponding values in the HF and CR populations were $73.9 \%$ and $35.7 \%$, respectively. 
Figure 2. Frequency distributions of predicted probabilities of death, by population, outcome, and method

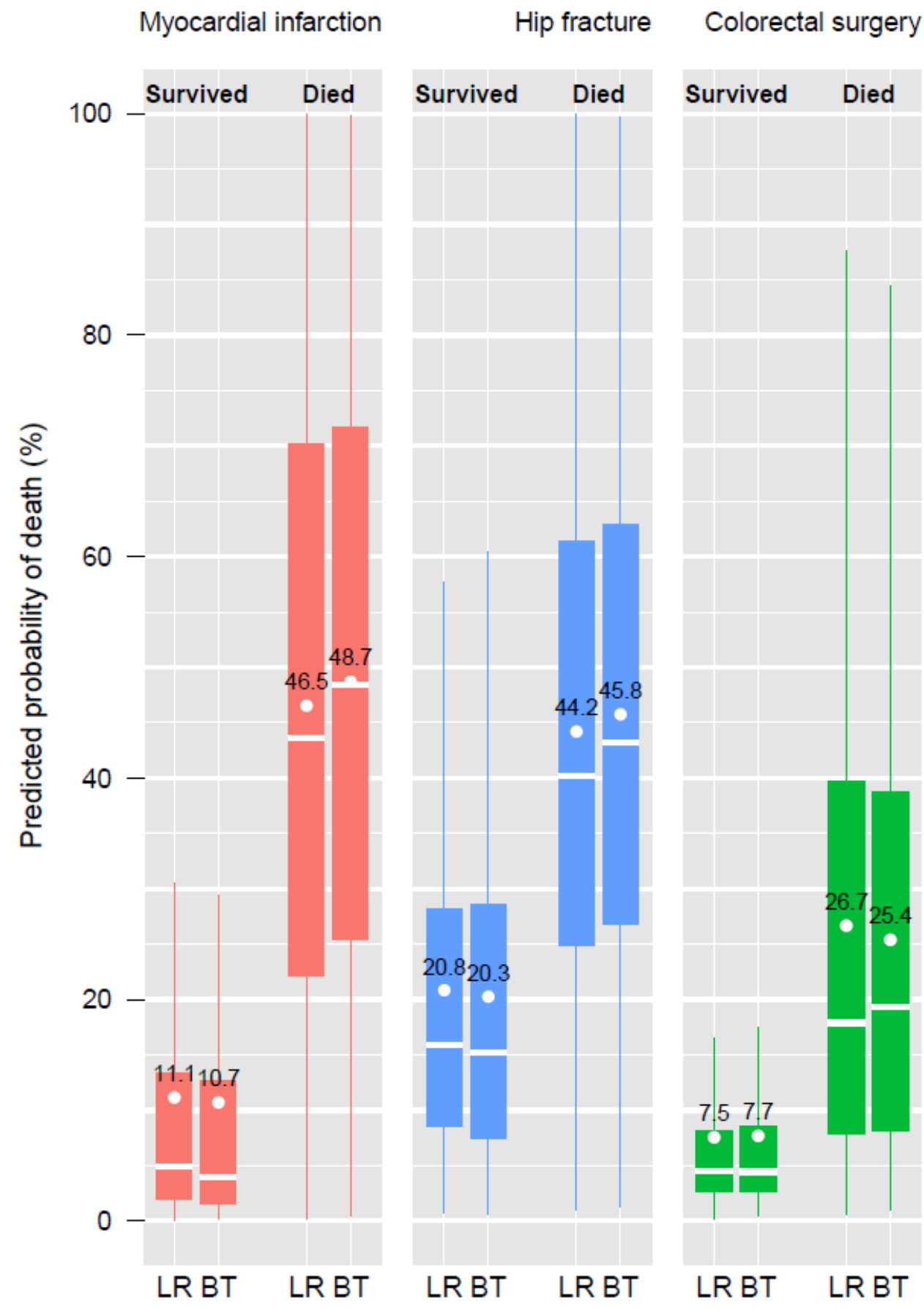

LR: logistic regression; BT: boosted trees. Boxes are drawn from the lower to upper quartile of predicted probabilities with a white horizontal line at the median value. Annotated values and white dots correspond to mean values. Whiskers are drawn to the most extreme predicted probabilities that are no more than 1.5 times the interquartile range from the box. 
Figure 3. Calibration plots for the logistic regression and boosted tree models, by population, corrected for optimism using 250 bootstrap samples (shown with line of perfect calibration)

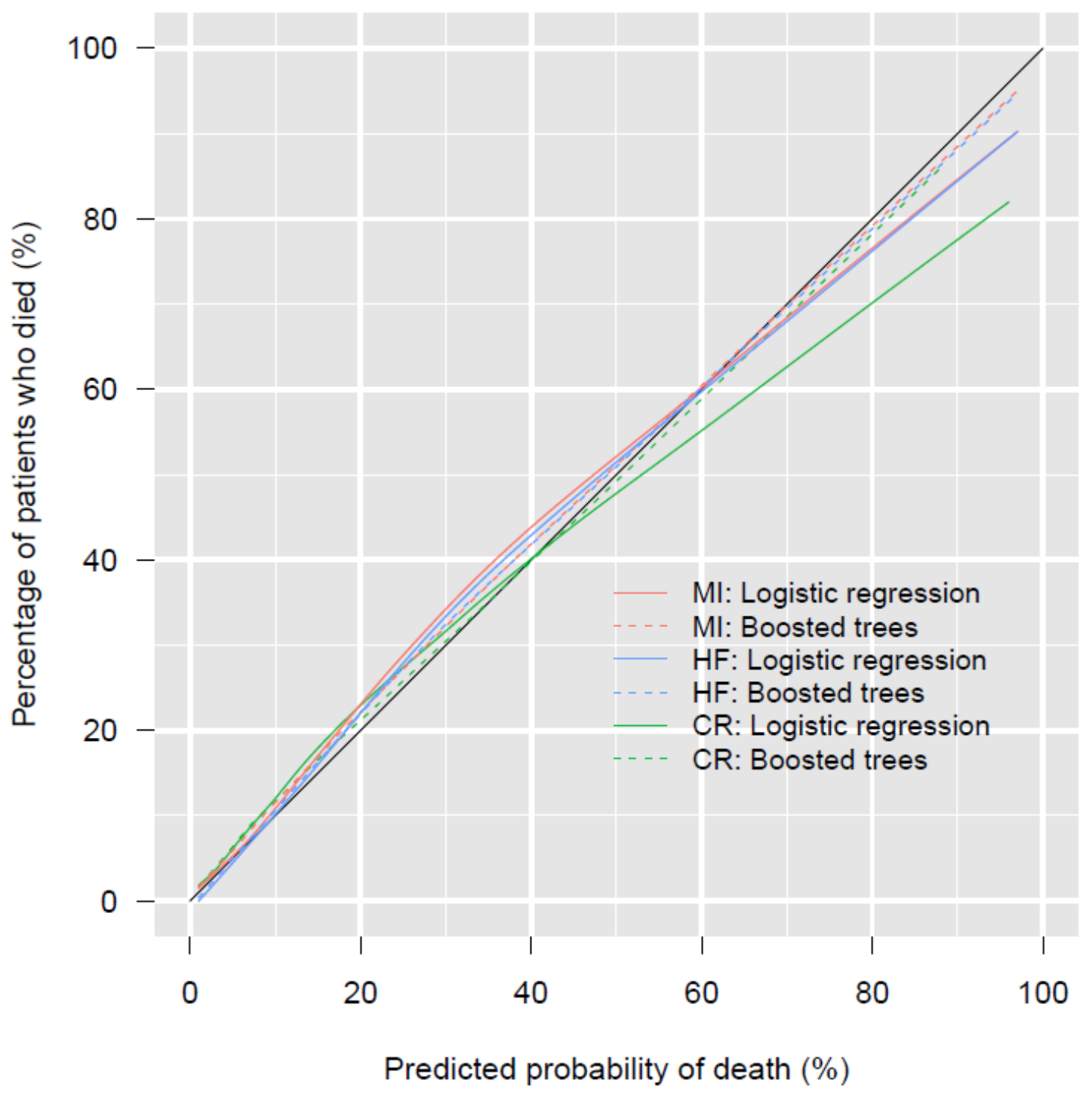

MI: myocardial infarction; HF: hip fracture; CR: colorectal surgery. In the MI and HF populations, $3.5 \%$ of predicted probabilities were equal to or greater than $80 \%$. In the CR population, $2.8 \%$ of predicted probabilities were equal to or greater than $50 \%$. The black $45^{\circ}$ line represents perfect calibration. 


\section{Appendix}

Page

A1 Tuning parameters of boosted regression trees 2

A2 Methods of the secondary analyses 3

A3 $\mathrm{R}$ code for the different estimation methods 5

A4 Important predictors in the logistic regression and boosted tree models 6

A5 Frequent ICD-10 codes recorded for patients whose predicted risks of death were in the 7 top $5 \%$ of predictions, by method

A6 Calibration plots for the logistic regression models with no interactions and with interactions between three selected predictors, by population

A7 Apparent and optimism-adjusted prediction performance of the logistic regression and boosted tree models as estimated using 250 bootstrap samples

A8 Results of the secondary analyses

A9 Results of additional analyses in response to peer reviewers 


\section{Appendix A1. Tuning parameters of boosted regression trees}

Boosted trees are an ensemble of individual trees whose predictions are passed to the next tree in the sequence to improve upon. The number of trees included in the ensemble is a parameter that can be tuned to improve performance. Each tree is developed by splitting a predictor at the best cut-point at each level of the tree. The maximum number of levels, or 'depth', of each tree is another tuning parameter, as are the minimum number of observations allowed to be at the end of one part of the tree and the observations used to fit each tree. The contribution of each tree to the overall ensemble is shrunk to reduce model overfitting; this shrinkage factor or 'learning rate' must also be tuned.

The study protocol ${ }^{1}$ stated that the boosted trees would be tuned by varying these five parameters (see table below) and selecting the model with the smallest negative log-likelihood across cross-validation folds. These results showed that different combinations of parameters generally gave similar minimum values of the negative log-likelihood across the range of boosting iterations ( 1 to 500). The final results were therefore obtained varying the number of boosting iterations only (see far right column below), using 250 bootstrap samples to calculate optimism and $95 \%$ confidence intervals.

\begin{tabular}{|l|l|r|r|}
\hline Parameter & Description & $\begin{array}{r}\text { Values tested in } \\
\text { cross-validation }\end{array}$ & $\begin{array}{r}\text { Values used in } \\
\text { final models }\end{array}$ \\
\hline Number of iterations & Maximum number of boosting iterations & $\begin{array}{r}1 \text { and 25 to 500 } \\
\text { (in steps of 25) }\end{array}$ & $\begin{array}{r}100 \text { to } 500 \text { (in } \\
\text { steps of 100) }\end{array}$ \\
\hline Learning rate & $\begin{array}{l}\text { Scales the contribution of each tree's predictions } \\
\text { by this value when added to the existing model }\end{array}$ & 0.05 and 0.1 & 0.1 \\
\hline Maximum tree depth & $\begin{array}{l}\text { Highest level of predictor interactions allowed in } \\
\text { a tree }\end{array}$ & 3 and 5 & 5 \\
\hline $\begin{array}{ll}\text { Minimum node } \\
\text { weight }\end{array}$ & $\begin{array}{l}\text { Stops tree splitting if the sum of observation } \\
\text { weights in a node is less than this parameter }\end{array}$ & 10 and 100 & 100 \\
\hline Subsample fraction & $\begin{array}{l}\text { Fraction of observations in the training dataset } \\
\text { randomly chosen to fit the next tree }\end{array}$ & 0.5 and 1 & \\
\hline & & & 1 \\
\hline
\end{tabular}

The scaled Brier scores and $c$-statistics obtained from the models tuned using cross-validation are shown below and were similar to those obtained using bootstrapping (given in the main text).

\begin{tabular}{|l|r|r|r|}
\hline & $\begin{array}{r}\text { Acute myocardial } \\
\text { infarction }\end{array}$ & Hip fracture & $\begin{array}{r}\text { Major colorectal } \\
\text { cancer surgery }\end{array}$ \\
\hline Scaled Brier score (\%) & & & 17.0 \\
\hline Logistic regression & 34.4 & 22.8 & 15.2 \\
\hline Boosted trees & 35.6 & 23.6 & 0.809 \\
\hline $\boldsymbol{c}$-statistic & & & 0.799 \\
\hline Logistic regression & 0.883 & 0.798 & 0.802 \\
\hline Boosted trees & 0.888 & & \\
\hline
\end{tabular}

1. Cowling TE, Cromwell DA, Sharples LD, van der Meulen J. Protocol for an observational study evaluating new approaches to modelling diagnostic information from large administrative hospital datasets. medRxiv 2019:19011338. doi: 10.1101/19011338. 


\section{Appendix A2. Methods of the secondary analyses}

\section{Five-year look-back period}

The main analysis defined a binary predictor for each ICD-10 code based on whether it was recorded or not within one year before the index date. A secondary analysis extended this 'look-back period' to five years (1825 days) to account for more diagnostic information. The frequency threshold for including ICD-10 codes was set at $1 \%$ so that the numbers of ICD-10 code predictors were similar to in the main analysis (which had a $0.5 \%$ threshold but shorter look-back period).

\begin{tabular}{|c|c|c|c|}
\hline & $\begin{array}{r}\text { Acute myocardial } \\
\text { infarction }\end{array}$ & Hip fracture & $\begin{array}{r}\text { Major colorectal } \\
\text { cancer surgery }\end{array}$ \\
\hline \multicolumn{4}{|l|}{ ICD-10 codes in 1-year look-back period } \\
\hline Number of codes included* & 202 & 257 & 209 \\
\hline Median frequencies (\%) of codes (IQR) & $1.6(0.8$ to 3.4$)$ & $1.8(0.8$ to 4.2$)$ & $1.6(0.9$ to 4.5$)$ \\
\hline Median number of codes per patient (IQR) & $6(4$ to 10$)$ & $9(6$ to 14$)$ & $7(4$ to 11$)$ \\
\hline \multicolumn{4}{|l|}{ ICD-10 codes in 5-year look-back period } \\
\hline Number of ICD-10 codes included* & 206 & 251 & 182 \\
\hline Median frequencies (\%) of codes (IQR) & $2.7(1.5$ to 5.4$)$ & $3.3(1.7$ to 7.1$)$ & 2.7 (1.6 to 6.6$)$ \\
\hline Median number of codes per patient (IQR) & $9(5$ to 15$)$ & $13(8$ to 21$)$ & $8(5$ to 13$)$ \\
\hline $\begin{array}{l}\text { Median number of days to last record of a } \\
\text { given code (IQR) }\end{array}$ & $0(0$ to 506$)$ & $2(0$ to 548$)$ & $4(0$ to 136$)$ \\
\hline
\end{tabular}

$\mathrm{IQR}=$ interquartile range. *Relative frequency of each three-character code was at least $0.5 \%$ (one-year look-back) or $1 \%$ (five-year look-back) in the given population.

We first estimated associations between the outcome and predictors (now defined using a five-year look-back period) using logistic regression. We then supplemented this model with an extra variable for each ICD-10 code which recorded the number of days before the index date that each code was last recorded (if at all). The resulting models assumed linear associations for these timing variables and were again estimated using logistic regression (see $\operatorname{protocol}^{1}$ for model equation). To model nonlinear associations for the timing variables, we also fitted generalised additive models with smoothing splines (with three degrees of freedom) for the continuous variables.

For the gradient boosted trees, a single predictor for each ICD-10 code was used which recorded the number of days before the index date that the code was last recorded (from 0 to 1825 days). If a patient did not have a given code recorded, the value of the variable for that code was set to a number (2000) that was arbitrarily larger than the maximum recorded value of 1825; the exact larger number chosen was arbitrary as trees dichotomise variables at optimal cut points. The trees were again fitted using the XGBoost algorithm and the tuning parameter values in Appendix A1. 
In each population, we added restricted cubic splines with three knots for the age and socioeconomic status variables in the logistic regression models. In the same models, we also included two-way interactions between three predictors. In the myocardial infarction population, these predictors were age, heart failure (I50), and cardiac arrest (I46). In the hip fracture population, the relevant predictors were age, sex, and other medical care (Z51). In the colorectal surgery population, the relevant predictors were age, secondary cancer of the lymph nodes (C77), and secondary cancer of the respiratory and digestive organs $(\mathrm{C} 78)$. These variables were chosen as they were important predictors (Appendix A4) and were relatively frequent among patients whose predicted risks of death were in the top 5\% (Appendix A5); this part of the predicted risk distribution was poorly calibrated in the logistic regression models that did not include interactions. To assess the effects on calibration, we plotted calibration curves for these models without and with splines and interactions (Appendix A6).

\section{Random forests and neural networks}

In addition to boosted trees, random forests and neural networks are two of the most popular machine learning approaches for analysing structured healthcare data. Like boosted trees, they model interactions between predictors by design but differ in how the model is constructed.

Random forests are an ensemble of individual trees in which predictions are averaged over all trees. A key difference to boosted trees is that random forest algorithms do not pass the predictions of one tree to the next tree in a sequence of trees. A defining characteristic of random forests is that the predictors used to split the tree are chosen at random at each split. This decorrelates trees to reduce the variance of their averaged predictions. The number of predictors to be randomly sampled at each split is a tuning parameter often set as the square root of the total number of predictors; we also tested twice the square root as an alternative value of this parameter. The other tuning parameter we varied was the minimum number of observations allowed to be in an end 'node' of the tree, which we set at 10 and 100. We fitted 500 trees in each random forest model as default in the ranger package in $\mathrm{R}$.

Neural networks model an outcome using an intermediate set of unobserved, or 'hidden', variables which themselves are linear combinations of the original predictors. The number of intermediate layers of hidden variables can be varied, as can the number of variables in each layer, to improve performance. We fitted models with a single intermediate layer and two or four hidden variables in this layer. As neural networks are highly flexible, they tend to over-fit the relationship between predictors and the outcome. To address this, a penalisation term, or 'weight decay', can be used. We tested weight decays of 0 (no decay) and 0.1 in each model. All predictors were mean-standardised before fitting the models using the nnet package in $\mathrm{R}$.

The values of tuning parameters that minimised the negative log-likelihood across five repeats of 5fold cross-validation were used to develop the final random forest and neural network models.

1. Cowling TE, Cromwell DA, Sharples LD, van der Meulen J. Protocol for an observational study evaluating new approaches to modelling diagnostic information from large administrative hospital datasets. medRxiv 2019:19011338. doi: 10.1101/19011338. 


\section{Appendix A3. R code used to implement the different estimation methods}

The data were stored in the data frame 'dfModel' with the outcome status ('mort') recorded in the first column. The predictor variables (age, sex, socioeconomic status and ICD-10 code predictors) were recorded in the other columns of the data frame.

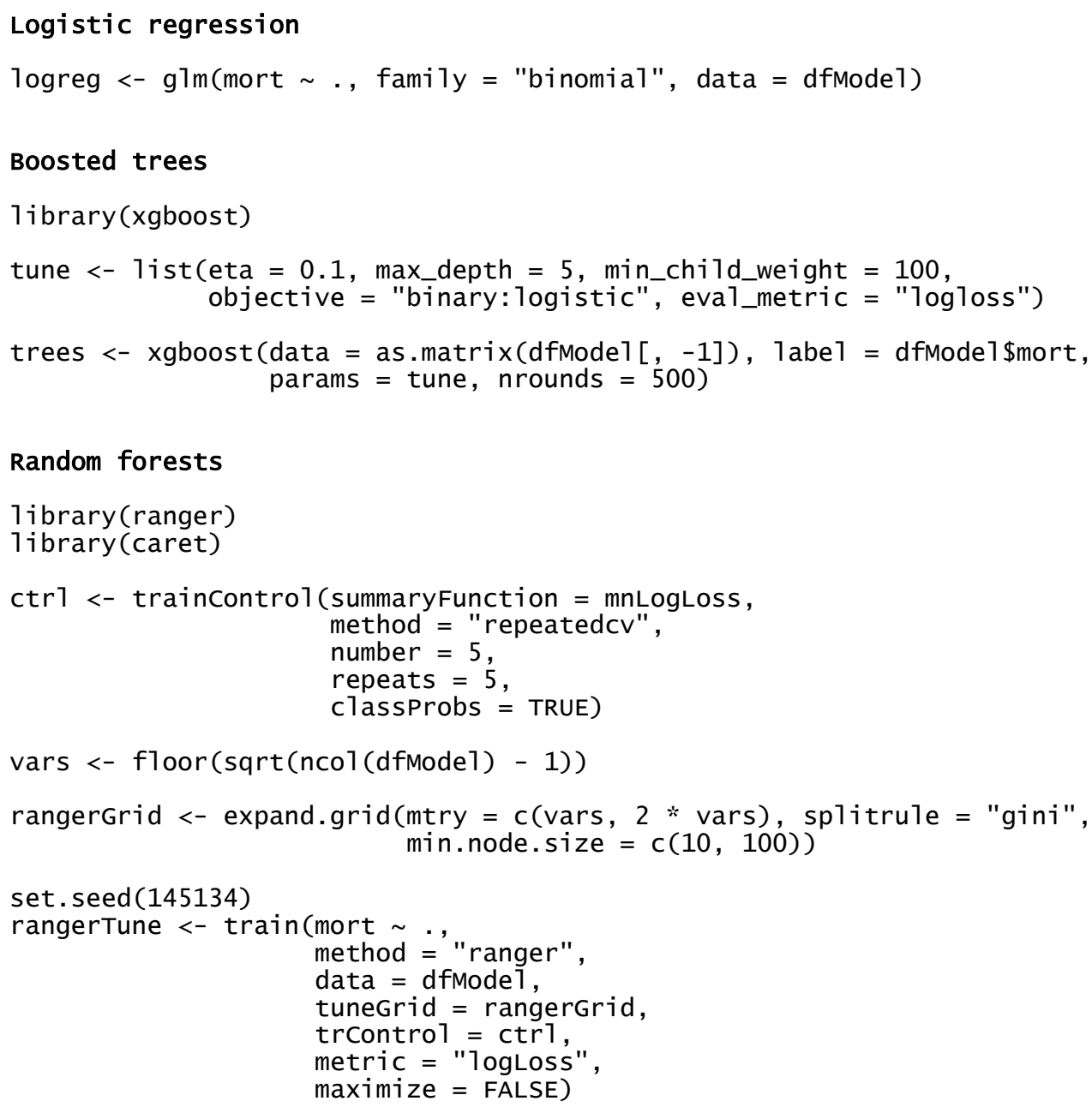




\section{Appendix A4. Important predictors in the logistic regression and boosted tree models}

Logistic regression

\begin{tabular}{|c|c|c|c|c|c|c|c|c|}
\hline \multicolumn{3}{|c|}{ Myocardial infarction } & \multicolumn{2}{|r|}{ Hip fracture } & $\chi^{2}$ & \multicolumn{2}{|r|}{ Colorectal surgery } & $\chi^{2}$ \\
\hline Age & & 21.2 & Age & & 18.3 & $\mathrm{C} 78$ & $\begin{array}{l}\text { Secondary malignant } \\
\text { neoplasm of respiratory } \\
\text { and digestive organs }\end{array}$ & 27.9 \\
\hline I46 & Cardiac arrest & 14.1 & $\mathrm{Z} 51$ & $\begin{array}{l}\text { Other medical care (e.g. } \\
\text { chemotherapy) }\end{array}$ & 5.9 & Age & & 7.9 \\
\hline R57 & $\begin{array}{l}\text { Shock, not elsewhere } \\
\text { classified }\end{array}$ & 4.9 & F03 & Unspecified dementia & 5.0 & I46 & Cardiac arrest & 7.0 \\
\hline Z51 & $\begin{array}{l}\text { Other medical care } \\
\text { (e.g. chemotherapy) }\end{array}$ & 3.9 & Sex & & 3.0 & C77 & $\begin{array}{l}\text { Secondary and } \\
\text { unspecified malignant } \\
\text { neoplasm of lymph nodes }\end{array}$ & 5.4 \\
\hline $\mathrm{I} 50$ & Heart failure & 2.9 & I46 & Cardiac arrest & 2.9 & K65 & Peritonitis & 3.0 \\
\hline G93 & Other disorders of brain & 1.7 & $\mathrm{C} 78$ & $\begin{array}{l}\text { Secondary malignant } \\
\text { neoplasm of respiratory } \\
\text { and digestive organs }\end{array}$ & 2.4 & $\mathrm{Z} 51$ & $\begin{array}{l}\text { Other medical care (e.g. } \\
\text { chemotherapy) }\end{array}$ & 2.5 \\
\hline N17 & Acute renal failure & 1.5 & F01 & Vascular dementia & 2.4 & D12 & $\begin{array}{l}\text { Benign neoplasm of } \\
\text { colon, rectum, anus, and a } \\
\text { nal canal }\end{array}$ & 1.6 \\
\hline $\mathrm{C} 78$ & $\begin{array}{l}\text { Secondary malignant } \\
\text { neoplasm of respiratory } \\
\text { and digestive organs }\end{array}$ & 1.4 & $\mathrm{C} 34$ & $\begin{array}{l}\text { Malignant neoplasm of } \\
\text { bronchus and lung }\end{array}$ & 1.9 & C79 & $\begin{array}{l}\text { Secondary malignant } \\
\text { neoplasm of other sites }\end{array}$ & 1.5 \\
\hline $\mathrm{C} 34$ & $\begin{array}{l}\text { Malignant neoplasm of } \\
\text { bronchus and lung }\end{array}$ & 0.9 & C79 & $\begin{array}{l}\text { Secondary malignant } \\
\text { neoplasm of other sites }\end{array}$ & 1.8 & K55 & $\begin{array}{l}\text { Vascular disorders of } \\
\text { intestine }\end{array}$ & 1.1 \\
\hline F03 & Unspecified dementia & 0.8 & I50 & Heart failure & 1.7 & I 48 & $\begin{array}{l}\text { Atrial fibrillation and } \\
\text { flutter }\end{array}$ & 0.9 \\
\hline
\end{tabular}

The variable importance measure, $\boldsymbol{\chi}^{2}$, is the partial Wald chi-square statistic for a given variable as a percentage of the statistic for the overall model.

\section{Boosted trees}

\begin{tabular}{|c|c|c|c|c|c|c|c|c|}
\hline \multicolumn{3}{|c|}{ Myocardial infarction } & \multicolumn{3}{|c|}{ Hip fracture } & \multicolumn{3}{|c|}{ Colorectal surgery } \\
\hline & & Gain & & & Gain & & & Gain \\
\hline Age & & 38.9 & Age & & 21.4 & $\mathrm{C} 78$ & $\begin{array}{l}\text { Secondary malignant } \\
\text { neoplasm of respiratory } \\
\text { and digestive organs }\end{array}$ & 27.2 \\
\hline I46 & Cardiac arrest & 11.6 & $\mathrm{Z} 51$ & $\begin{array}{l}\text { Other medical care (e.g. } \\
\text { chemotherapy) }\end{array}$ & 8.1 & Age & & 17.1 \\
\hline N17 & Acute renal failure & 6.3 & $\mathrm{~J} 18$ & $\begin{array}{l}\text { Pneumonia, organism } \\
\text { unspecified }\end{array}$ & 6.8 & K65 & Peritonitis & 5.1 \\
\hline $\mathrm{I} 50$ & Heart failure & 5.6 & F03 & Unspecified dementia & 6.7 & N17 & Acute renal failure & 5.1 \\
\hline Z51 & $\begin{array}{l}\text { Other medical care (e.g. } \\
\text { chemotherapy) }\end{array}$ & 3.9 & I50 & Heart failure & 4.3 & $\mathrm{C} 77$ & $\begin{array}{l}\text { Secondary and } \\
\text { unspecified malignant } \\
\text { neoplasm of lymph nodes }\end{array}$ & 4.8 \\
\hline R57 & $\begin{array}{l}\text { Shock, not elsewhere } \\
\text { classified }\end{array}$ & 3.9 & Sex & & 3.9 & E87 & $\begin{array}{l}\text { Other disorders of fluid, } \\
\text { electrolyte, and acid- } \\
\text { base balance }\end{array}$ & 3.8 \\
\hline E87 & $\begin{array}{l}\text { Other disorders of fluid, } \\
\text { electrolyte, and acid- } \\
\text { base balance }\end{array}$ & 3.0 & W19 & Unspecified fall & 2.9 & $\begin{array}{l}\text { Socio. } \\
\text { status }\end{array}$ & & 3.5 \\
\hline $\mathrm{J} 18$ & $\begin{array}{l}\text { Pneumonia, organism } \\
\text { unspecified }\end{array}$ & 2.2 & I46 & Cardiac arrest & 2.8 & $\mathrm{Z} 51$ & $\begin{array}{l}\text { Other medical care (e.g. } \\
\text { chemotherapy) }\end{array}$ & 2.8 \\
\hline C78 & $\begin{array}{l}\text { Secondary malignant } \\
\text { neoplasm of respiratory } \\
\text { and digestive organs }\end{array}$ & 1.5 & N17 & Acute renal failure & 2.6 & A41 & Other septicemia & 2.8 \\
\hline N18 & Chronic renal failure & 1.4 & G30 & Alzheimer's disease & 2.5 & J96 & $\begin{array}{l}\text { Respiratory failure, not } \\
\text { elsewhere classified }\end{array}$ & 2.3 \\
\hline
\end{tabular}
from this variable's splits in the trees in minimising the negative log-likelihood. 


\section{Appendix A5. Frequent ICD-10 codes recorded for patients whose predicted risks of death were in the top $5 \%$ of predictions, by method}

Myocardial infarction $(\mathrm{n}=10$ 006)

\begin{tabular}{|c|c|c|c|c|c|c|c|}
\hline \multicolumn{4}{|c|}{ Logistic regression - Prob(death $) \geq 0.725$} & \multicolumn{4}{|c|}{ Boosted trees - Prob $($ death $) \geq 0.721$} \\
\hline \multicolumn{2}{|c|}{ Code } & \multirow{2}{*}{$\begin{array}{l}\text { n } \\
6527\end{array}$} & \multirow{2}{*}{$\begin{array}{l}\text { \% } \\
65.2\end{array}$} & \multicolumn{2}{|l|}{ Code } & \multirow{2}{*}{$\begin{array}{l}\text { n } \\
6016\end{array}$} & \multirow{2}{*}{$\begin{array}{l}\% \\
60.1\end{array}$} \\
\hline $\mathrm{I} 10$ & Essential (primary) hypertension & & & $\mathrm{I} 10$ & $\begin{array}{l}\text { Essential (primary) } \\
\text { hypertension }\end{array}$ & & \\
\hline $\mathrm{I} 50$ & Heart failure & 6280 & 62.8 & $\mathrm{I} 50$ & Heart failure & 5506 & 55.0 \\
\hline $\mathrm{I} 25$ & Chronic ischemic heart disease & 5691 & 56.9 & $\mathrm{I} 25$ & $\begin{array}{l}\text { Chronic ischemic heart } \\
\text { disease }\end{array}$ & 5320 & 53.2 \\
\hline N17 & Acute renal failure & 5033 & 50.3 & N17 & Acute renal failure & 4536 & 45.3 \\
\hline Z86 & $\begin{array}{l}\text { Personal history of certain other } \\
\text { diseases }\end{array}$ & 4364 & 43.6 & Z86 & $\begin{array}{l}\text { Personal history of certain } \\
\text { other diseases }\end{array}$ & 4040 & 40.4 \\
\hline I48 & Atrial fibrillation and flutter & 4180 & 41.8 & I46 & Cardiac arrest & 3802 & 38.0 \\
\hline N18 & Chronic renal failure & 3834 & 38.3 & $\mathrm{I} 48$ & Atrial fibrillation and flutter & 3747 & 37.4 \\
\hline I46 & Cardiac arrest & 3647 & 36.4 & N18 & Chronic renal failure & 3381 & 33.8 \\
\hline E11 & $\begin{array}{l}\text { Non-insulin- } \\
\text { dependent diabetes mellitus }\end{array}$ & 3537 & 35.3 & E11 & $\begin{array}{l}\text { Non-insulin- } \\
\text { dependent diabetes mellitus }\end{array}$ & 3212 & 32.1 \\
\hline E87 & $\begin{array}{l}\text { Other disorders of fluid, electrolyte, } \\
\text { and acid-base balance }\end{array}$ & 3495 & 34.9 & Z92 & $\begin{array}{l}\text { Personal history of medical } \\
\text { treatment }\end{array}$ & 3076 & 30.7 \\
\hline
\end{tabular}

Hip fracture $(\mathrm{n}=8483)$

\begin{tabular}{|c|c|c|c|c|c|c|c|}
\hline \multicolumn{4}{|c|}{ Logistic regression - Prob(death $) \geq 0.739$} & \multicolumn{4}{|c|}{ Boosted trees - Prob(death) $\geq 0.731$} \\
\hline \multicolumn{2}{|l|}{ Code } & \multirow{2}{*}{$\begin{array}{l}\mathbf{n} \\
5069\end{array}$} & \multirow{2}{*}{$\begin{array}{l}\mathbf{\%} \\
59.8\end{array}$} & \multicolumn{2}{|l|}{ Code } & \multirow{2}{*}{$\begin{array}{l}n \\
4686\end{array}$} & \multirow{2}{*}{$\begin{array}{l}\% \\
55.2\end{array}$} \\
\hline $\mathrm{I} 10$ & Essential (primary) hypertension & & & $\mathrm{I} 10$ & $\begin{array}{l}\text { Essential (primary) } \\
\text { hypertension }\end{array}$ & & \\
\hline W19 & Unspecified fall & 5035 & 59.4 & W19 & Unspecified fall & 4668 & 55.0 \\
\hline $\mathrm{J} 18$ & Pneumonia, organism unspecified & 4368 & 51.5 & $\mathrm{~J} 18$ & $\begin{array}{l}\text { Pneumonia, organism } \\
\text { unspecified }\end{array}$ & 4129 & 48.7 \\
\hline I48 & Atrial fibrillation and flutter & 4216 & 49.7 & $\mathrm{I} 48$ & Atrial fibrillation and flutter & 3953 & 46.6 \\
\hline Z86 & $\begin{array}{l}\text { Personal history of certain other } \\
\text { diseases }\end{array}$ & 3855 & 45.4 & Z51 & $\begin{array}{l}\text { Other medical care (e.g. } \\
\text { chemotherapy) }\end{array}$ & 3586 & 42.3 \\
\hline N17 & Acute renal failure & 3748 & 44.2 & N17 & Acute renal failure & 3506 & 41.3 \\
\hline R29 & $\begin{array}{l}\text { Other symptoms and signs involving } \\
\text { the nervous and musculoskeletal } \\
\text { systems }\end{array}$ & 3537 & 41.7 & Z86 & $\begin{array}{l}\text { Personal history of certain } \\
\text { other diseases }\end{array}$ & 3429 & 40.4 \\
\hline $\mathrm{I} 50$ & Heart failure & 3483 & 41.1 & $\mathrm{I} 50$ & Heart failure & 3172 & 37.4 \\
\hline N18 & Chronic renal failure & 3381 & 39.9 & N18 & Chronic renal failure & 3134 & 36.9 \\
\hline Z51 & $\begin{array}{l}\text { Other medical care (e.g. } \\
\text { chemotherapy) }\end{array}$ & 3257 & 38.4 & R29 & $\begin{array}{l}\text { Other symptoms and signs } \\
\text { involving the nervous and } \\
\text { musculoskeletal systems }\end{array}$ & 2997 & 35.3 \\
\hline
\end{tabular}


Colorectal surgery $(\mathrm{n}=2826)$

\begin{tabular}{|c|c|c|c|c|c|c|c|}
\hline \multicolumn{4}{|c|}{ Logistic regression - Prob(death) $\geq 0.357$} & \multicolumn{4}{|c|}{ Boosted trees - Prob(death) $\geq 0.354$} \\
\hline \multicolumn{2}{|l|}{ Code } & & \multirow{2}{*}{$\begin{array}{l}\% \\
59.4\end{array}$} & \multicolumn{2}{|c|}{ Code } & \multirow{2}{*}{$\begin{array}{l}\mathbf{n} \\
1720\end{array}$} & \multirow{2}{*}{$\begin{array}{l}\mathbf{\%} \\
60.9\end{array}$} \\
\hline C78 & $\begin{array}{l}\text { Secondary malignant neoplasm of } \\
\text { respiratory and digestive organs }\end{array}$ & & & C78 & $\begin{array}{l}\text { Secondary malignant } \\
\text { neoplasm of respiratory and } \\
\text { digestive organs }\end{array}$ & & \\
\hline 10 & $\mathrm{E}$ & 1594 & 56.4 & I10 & $\begin{array}{l}\text { Essential (primary) } \\
\text { hypertension }\end{array}$ & 1596 & 56.5 \\
\hline$c 77$ & aph nodes & 1220 & 43.2 & C77 & $\begin{array}{l}\text { Secondary a } \\
\text { malignant } \mathrm{n} \\
\text { nodes }\end{array}$ & 1171 & 41.4 \\
\hline 286 & $\begin{array}{l}\text { Perso } \\
\text { diseas }\end{array}$ & 95 & 5.2 & N17 & Acute renal failure & 958 & 33.9 \\
\hline N17 & nal failure & 858 & 30.4 & Z86 & 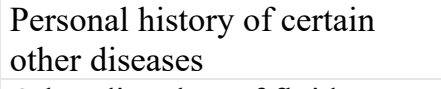 & 953 & 33.7 \\
\hline E87 & uid, electrolyte, & 812 & 28.7 & E87 & $\begin{array}{l}\text { Other disorders of fluid, } \\
\text { electrolyte, and acid- } \\
\text { base balance }\end{array}$ & 874 & 30.9 \\
\hline Z92 & $y$ of medical treatment & 809 & 28.6 & I48 & Atrial fibrillation and flutter & 804 & 28.5 \\
\hline $\mathrm{I} 48$ & Atrial fibrills & 791 & 28.0 & K56 & $\begin{array}{l}\text { Paralytic ileus and intestinal } \\
\text { obstruction without hernia }\end{array}$ & 778 & 27.5 \\
\hline K56 & $\begin{array}{l}\text { Paralytic ileus and intestinal } \\
\text { obstruction without hernia }\end{array}$ & 784 & 27.7 & J18 & $\begin{array}{l}\text { Pneumonia, organism } \\
\text { unspecified }\end{array}$ & 749 & 26.5 \\
\hline <63 & Other diseases of intestine & 723 & 25.6 & K63 & Other diseases of intestine & 719 & 25.4 \\
\hline
\end{tabular}


Appendix A6. Optimism-adjusted calibration plots and performance measures for the logistic regression models of the main analysis and with splines and selected interactions

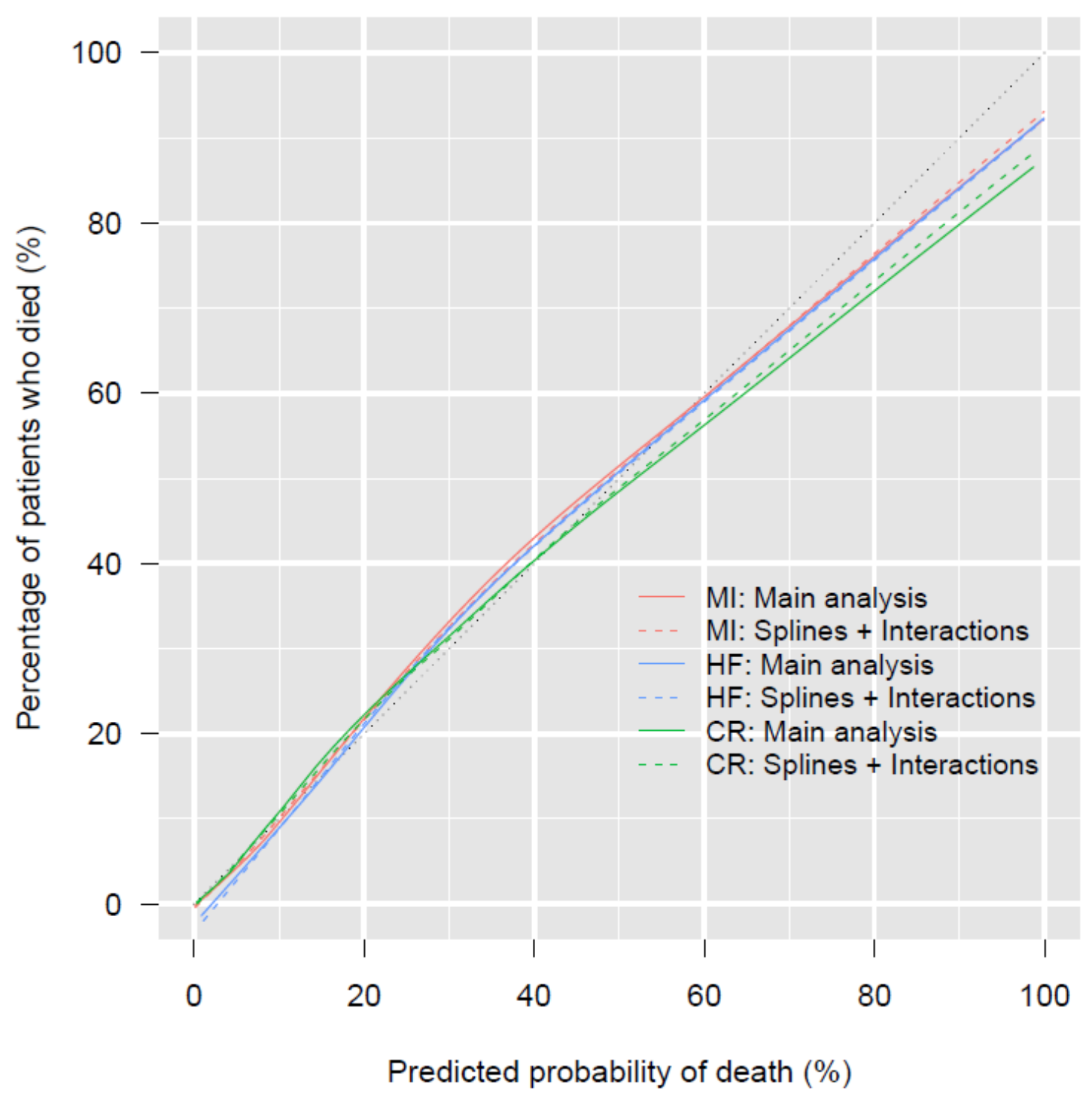

\begin{tabular}{|c|r|r|r|}
\hline Scaled Brier score (\%) & Myocardial infarction & Hip fracture & Colorectal surgery \\
\hline No splines or interactions & & & 22.8 \\
\hline With splines and interactions & 34.6 & 22.9 & 17.2 \\
\hline $\boldsymbol{c}$-statistic & & & 17.9 \\
\hline No splines or interactions & 0.884 & 0.798 & 0.811 \\
\hline With splines and interactions & 0.885 & 0.799 & 0.810 \\
\hline
\end{tabular}

MI: myocardial infarction; HF: hip fracture; CR: colorectal surgery. Two-way interactions were included between: age, cardiac arrest (I46), and heart failure (I50) in the MI population; age, sex, and other medical care (Z51) in the HF population; and age, nodal metastases (C77), and respiratory/digestive metastases (C78) in the colorectal surgery population. Age and socioeconomic status were modelled using restricted cubic splines with three knots. 
Appendix A7. Apparent and optimism-adjusted prediction performance of the logistic regression and boosted tree models as estimated using 250 bootstrap samples

\begin{tabular}{|c|c|c|c|c|c|c|c|c|c|}
\hline & \multicolumn{3}{|c|}{ Myocardial infarction } & \multicolumn{3}{|c|}{ Hip fracture } & \multicolumn{3}{|c|}{ Colorectal surgery } \\
\hline & App. & Opt. & Adj. & App. & Opt. & Adj. & App. & Opt. & Adj. \\
\hline \multicolumn{10}{|c|}{ Scaled Brier score (\%) } \\
\hline Logistic regression & 34.9 & 0.3 & 34.6 & 23.1 & 0.3 & 22.8 & 18.5 & 1.3 & 17.2 \\
\hline \multicolumn{10}{|l|}{ Boosted trees: } \\
\hline 100 iterations & 36.0 & 0.8 & 35.1 & 23.9 & 0.9 & 22.9 & 17.5 & 1.9 & 15.6 \\
\hline 200 iterations & 37.4 & 1.3 & 36.0 & 25.1 & 1.5 & 23.6 & 18.7 & 3.0 & 15.7 \\
\hline 300 iterations & 38.0 & 1.7 & 36.3 & 25.8 & 2.0 & 23.8 & 19.3 & 3.7 & 15.6 \\
\hline 400 iterations & 38.5 & 2.1 & 36.4 & 26.3 & 2.4 & 23.9 & 19.8 & 4.3 & 15.5 \\
\hline 500 iterations & 38.9 & 2.4 & 36.5 & 26.7 & 2.7 & 24.0 & 20.3 & 4.8 & 15.5 \\
\hline \multicolumn{10}{|l|}{$c$-statistic } \\
\hline Logistic regression & 0.885 & 0.001 & 0.884 & 0.800 & 0.002 & 0.798 & 0.819 & 0.008 & 0.811 \\
\hline \multicolumn{10}{|l|}{ Boosted trees: } \\
\hline 100 iterations & 0.888 & 0.003 & 0.886 & 0.803 & 0.005 & 0.798 & 0.813 & 0.011 & 0.802 \\
\hline 200 iterations & 0.893 & 0.004 & 0.889 & 0.809 & 0.008 & 0.801 & 0.820 & 0.017 & 0.803 \\
\hline 300 iterations & 0.895 & 0.005 & 0.890 & 0.813 & 0.010 & 0.803 & 0.824 & 0.021 & 0.803 \\
\hline 400 iterations & 0.897 & 0.006 & 0.890 & 0.815 & 0.012 & 0.803 & 0.827 & 0.024 & 0.802 \\
\hline 500 iterations & 0.898 & 0.007 & 0.891 & 0.818 & 0.014 & 0.804 & 0.829 & 0.027 & 0.803 \\
\hline \multicolumn{10}{|c|}{ Calibration-in-the-large } \\
\hline Logistic regression & 0 & 0.001 & -0.001 & 0 & 0.000 & 0.000 & 0 & 0.000 & 0.000 \\
\hline \multicolumn{10}{|l|}{ Boosted trees: } \\
\hline 100 iterations & 0.000 & 0.000 & 0.000 & 0.000 & -0.001 & 0.001 & 0.000 & -0.002 & 0.001 \\
\hline 200 iterations & 0.000 & 0.000 & 0.000 & 0.000 & -0.001 & 0.001 & 0.000 & -0.002 & 0.002 \\
\hline 300 iterations & 0.000 & 0.000 & 0.000 & 0.000 & -0.001 & 0.001 & 0.000 & -0.003 & 0.003 \\
\hline 400 iterations & 0.000 & 0.000 & 0.000 & 0.000 & -0.001 & 0.001 & 0.000 & -0.003 & 0.003 \\
\hline 500 iterations & 0.000 & 0.000 & 0.000 & 0.000 & -0.001 & 0.001 & 0.000 & -0.004 & 0.004 \\
\hline \multicolumn{10}{|l|}{ Calibration slope } \\
\hline Logistic regression & 1 & 0.007 & 0.993 & 1 & 0.011 & 0.989 & 1 & 0.039 & 0.961 \\
\hline \multicolumn{10}{|l|}{ Boosted trees: } \\
\hline 100 iterations & 1.120 & 0.020 & 1.100 & 1.173 & 0.036 & 1.138 & 1.109 & 0.057 & 1.052 \\
\hline 200 iterations & 1.079 & 0.031 & 1.048 & 1.120 & 0.052 & 1.068 & 1.073 & 0.086 & 0.988 \\
\hline 300 iterations & 1.066 & 0.040 & 1.026 & 1.103 & 0.066 & 1.037 & 1.078 & 0.107 & 0.970 \\
\hline 400 iterations & 1.059 & 0.048 & 1.011 & 1.096 & 0.078 & 1.018 & 1.085 & 0.124 & 0.961 \\
\hline 500 iterations & 1.058 & 0.055 & 1.003 & 1.094 & 0.089 & 1.006 & 1.096 & 0.139 & 0.957 \\
\hline \multicolumn{10}{|c|}{ Integrated calibration index } \\
\hline Logistic regression & 0.012 & 0.000 & 0.012 & 0.015 & 0.000 & 0.015 & 0.007 & 0.000 & 0.007 \\
\hline \multicolumn{10}{|l|}{ Boosted trees: } \\
\hline 100 iterations & 0.011 & 0.001 & 0.010 & 0.019 & 0.002 & 0.017 & 0.007 & 0.002 & 0.005 \\
\hline 200 iterations & 0.008 & 0.002 & 0.006 & 0.014 & 0.004 & 0.011 & 0.005 & 0.004 & 0.001 \\
\hline 300 iterations & 0.006 & 0.002 & 0.004 & 0.012 & 0.005 & 0.007 & 0.005 & 0.005 & 0.000 \\
\hline 400 iterations & 0.006 & 0.003 & 0.003 & 0.012 & 0.006 & 0.005 & 0.005 & 0.006 & -0.001 \\
\hline 500 iterations & 0.005 & 0.003 & 0.002 & 0.011 & 0.007 & 0.004 & 0.006 & 0.007 & -0.001 \\
\hline
\end{tabular}




\section{Appendix A8. Results of the secondary analyses}

\section{Five-year look-back period}

The boosted trees attained the largest scaled Brier scores and $c$-statistics in each population, while the logistic regression models that did not account for the timings had the lowest scores (see table below). However, the boosted trees performed comparably to those from the main analysis (which only used a one-year look-back period). This may be partly because most ICD-10 codes were last recorded within a few days of the index dates (see Appendix A2). The approach may work better for non-hospitalised populations with more variation in the times since diagnosis codes were last recorded.

\begin{tabular}{|c|c|c|c|}
\hline & $\begin{array}{c}\text { Acute myocardial } \\
\text { infarction }\end{array}$ & Hip fracture & $\begin{array}{c}\text { Major colorectal } \\
\text { cancer surgery }\end{array}$ \\
\hline \multicolumn{4}{|l|}{ Scaled Brier score (\%) } \\
\hline Boosted trees & 36.2 & 24.1 & 17.2 \\
\hline Generalised additive models & 34.4 & 23.1 & 15.1 \\
\hline Logistic regression with time effects & 33.7 & 22.2 & 14.9 \\
\hline Logistic regression & 32.2 & 20.8 & 14.8 \\
\hline \multicolumn{4}{|l|}{$c$-statistic } \\
\hline Boosted trees & 0.889 & 0.804 & 0.807 \\
\hline Generalised additive models & 0.883 & 0.799 & 0.796 \\
\hline Logistic regression with time effects & 0.880 & 0.794 & 0.797 \\
\hline Logistic regression & 0.876 & 0.789 & 0.800 \\
\hline
\end{tabular}

\section{Random forests and neural networks}

The random forest models did not perform better than both the logistic regression and boosted tree models in any of the populations. Neural networks consistently performed worse than other models.

\begin{tabular}{|c|c|c|c|}
\hline & $\begin{array}{c}\text { Acute myocardial } \\
\text { infarction }\end{array}$ & Hip fracture & $\begin{array}{c}\text { Major colorectal } \\
\text { cancer surgery }\end{array}$ \\
\hline \multicolumn{4}{|c|}{ Scaled Brier score (\%) } \\
\hline Random forests & 35.1 & 22.1 & 16.1 \\
\hline Neural networks & 32.2 & 17.4 & 11.1 \\
\hline \multicolumn{4}{|l|}{$c$-statistic } \\
\hline Random forests & 0.887 & 0.795 & 0.808 \\
\hline Neural networks & 0.878 & 0.774 & 0.784 \\
\hline
\end{tabular}




\section{Appendix A9. Results of additional analyses in response to peer reviewers}

\section{Further combinations of tuning parameters}

The main analysis fitted boosted tree models with a maximum tree depth ('Max Tree Depth') of 5, learning rate ('eta') of 0.1 , minimum node weight ('min_child_weight') of 100 , and up to 500 boosting iterations (Appendix A1). Results for this combination can be seen as the pink line in the bottom left-hand panel of each figure below. The figures present the scaled Brier scores (estimated using five-fold cross-validation) when these tuning parameters were combined with different values. In each population, the maximum performance values were relatively insensitive to the choice of different combinations provided that the number of boosting iterations was tuned appropriately.

Myocardial infarction:

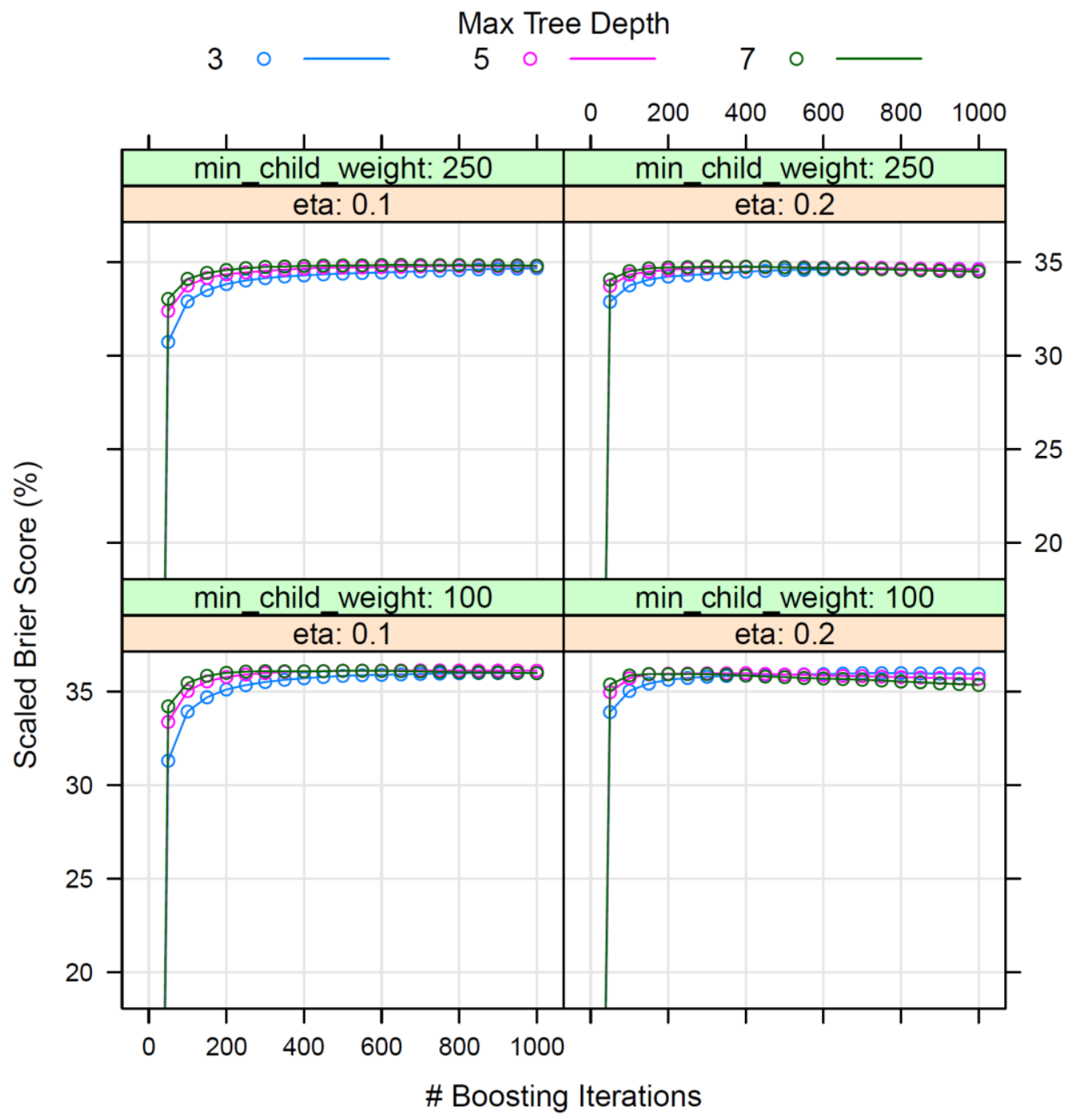


Hip fracture:

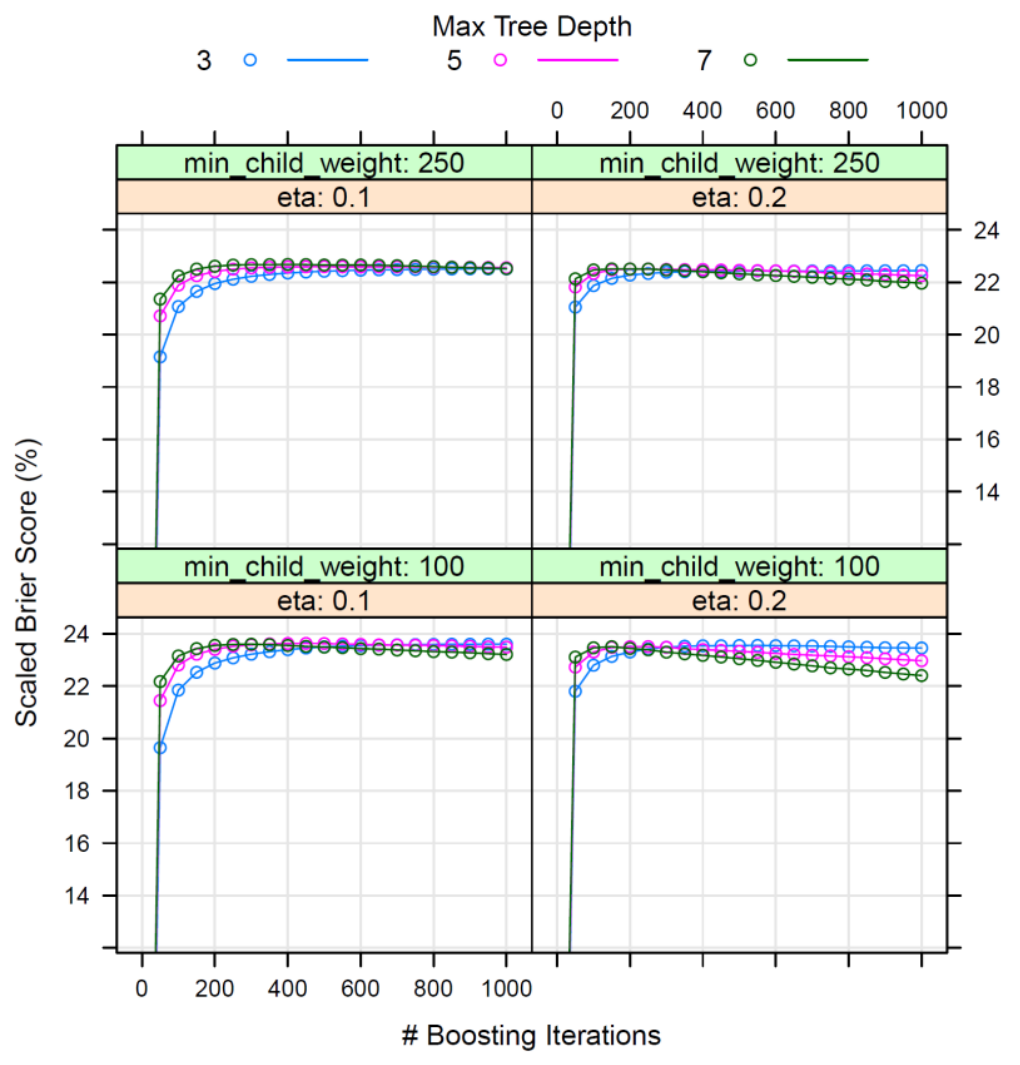

Colorectal surgery:

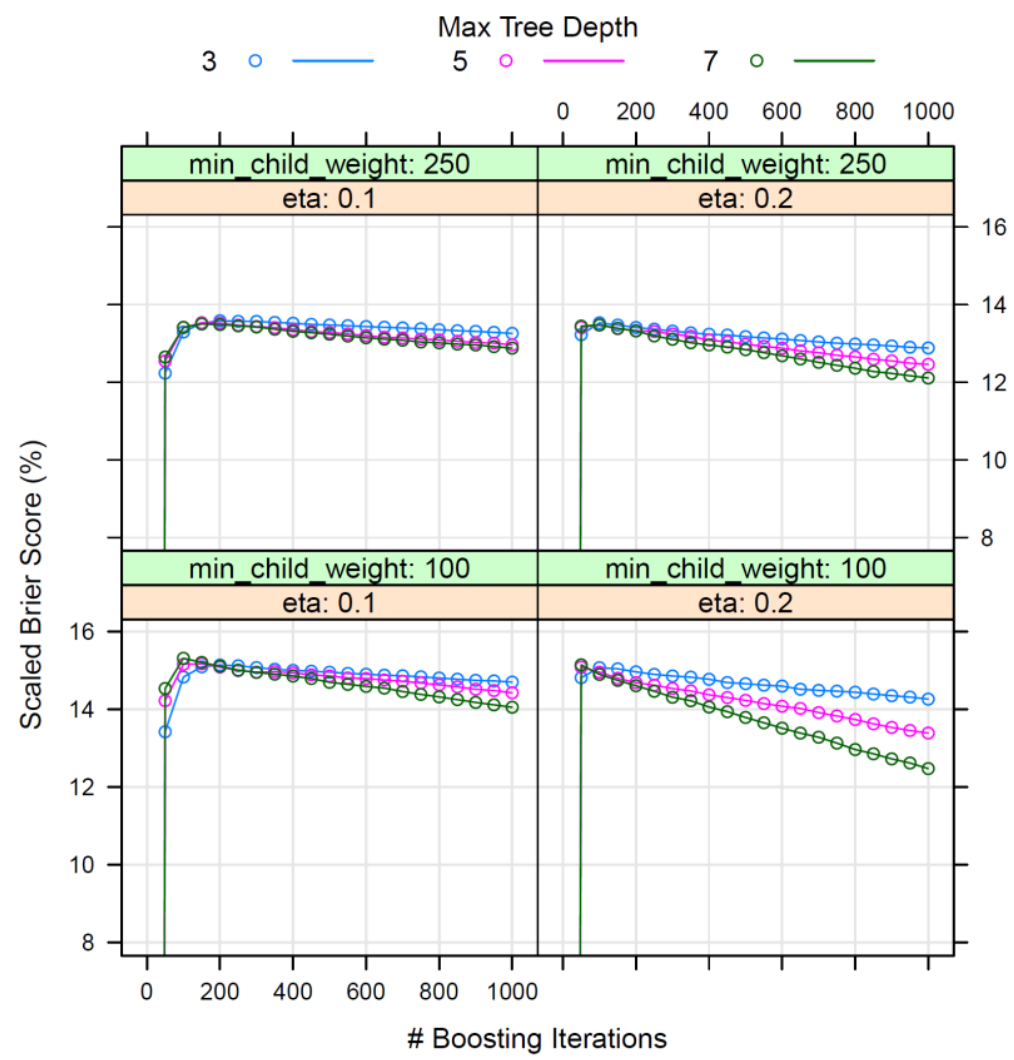


Frequency threshold of $0.1 \%$ for ICD codes

When only ICD codes with frequencies less than $0.1 \%$ (rather than $0.5 \%$ ) were excluded from the set of predictor variables, the number of included ICD codes approximately doubled in each population. However, the performance of the resulting models in the original data ('apparent performance') hardly changed, as shown below by population and frequency threshold $(0.5 \%$ or $0.1 \%)$.

\begin{tabular}{|c|c|c|c|c|c|c|}
\hline & \multicolumn{2}{|c|}{ Myocardial infarction } & \multicolumn{2}{|c|}{ Hip fracture } & \multicolumn{2}{|c|}{ Colorectal surgery } \\
\hline & $0.5 \%$ & $0.1 \%$ & $0.5 \%$ & $0.1 \%$ & $0.5 \%$ & $0.1 \%$ \\
\hline Number of ICD codes & 202 & 440 & 257 & 522 & 209 & 434 \\
\hline \multicolumn{7}{|l|}{ Scaled Brier score (\%): } \\
\hline Logistic regression & 34.9 & 35.7 & 23.1 & 24.0 & 18.5 & 20.0 \\
\hline \multicolumn{7}{|l|}{ Boosted trees: } \\
\hline 100 iterations & 36.0 & 36.0 & 23.9 & 23.8 & 17.5 & 17.5 \\
\hline 200 iterations & 37.4 & 37.3 & 25.1 & 25.1 & 18.7 & 18.7 \\
\hline 300 iterations & 38.0 & 38.0 & 25.8 & 25.8 & 19.3 & 19.3 \\
\hline 400 iterations & 38.5 & 38.4 & 26.3 & 26.2 & 19.8 & 19.8 \\
\hline 500 iterations & 38.9 & 38.8 & 26.7 & 26.7 & 20.3 & 20.3 \\
\hline \multicolumn{7}{|l|}{$c$-statistic: } \\
\hline Logistic regression & 0.885 & 0.887 & 0.800 & 0.805 & 0.819 & 0.827 \\
\hline \multicolumn{7}{|l|}{ Boosted trees: } \\
\hline 100 iterations & 0.888 & 0.888 & 0.803 & 0.803 & 0.813 & 0.813 \\
\hline 200 iterations & 0.893 & 0.893 & 0.809 & 0.810 & 0.820 & 0.820 \\
\hline 300 iterations & 0.895 & 0.895 & 0.813 & 0.813 & 0.824 & 0.824 \\
\hline 400 iterations & 0.897 & 0.896 & 0.815 & 0.816 & 0.827 & 0.827 \\
\hline 500 iterations & 0.898 & 0.898 & 0.818 & 0.818 & 0.829 & 0.829 \\
\hline
\end{tabular}

